\title{
ADULTS AS ECOLOGICAL ASSETS FOR POSITIVE YOUTH DEVELOPMENT: AN IN DEPTH EXAMINATION OF SOCIAL RESOURCES
}

\author{
A Dissertation \\ Presented to
}

The Faculty of the Curry School of Education

University of Virginia

In Partial Fulfillment of the Requirements for the Degree

Doctor of Philosophy

by

Shannon M. Varga, B.A.

May 2016 


\section{TABLE OF CONTENTS}

Page

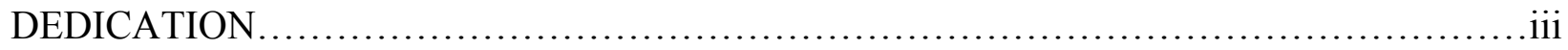

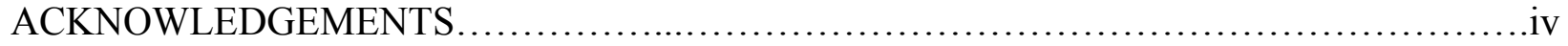

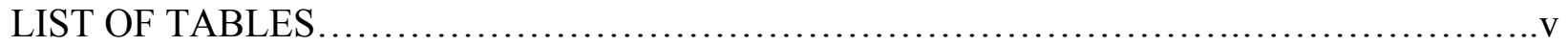

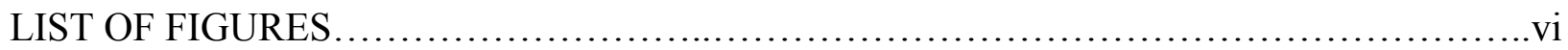

ELEMENTS

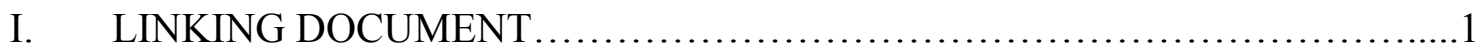

II. PAPER 1: "It's going to help me in life": Forms, Sources, and Functions of Social Support for Youth in Relationships With Non-parental Adults.................12

III. PAPER 2: Conceptualizing Social Capital Within a Positive Youth Development Framework: The Case of Youth Adult Relationships.........................43

IV. PAPER 3: Deconstructing Social Capital in Youth Adult Relationships..........68

\section{REFERENCES:}

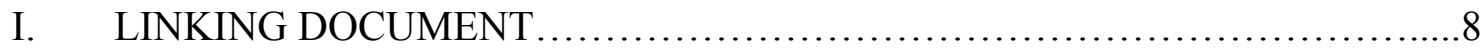

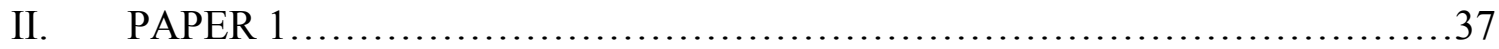

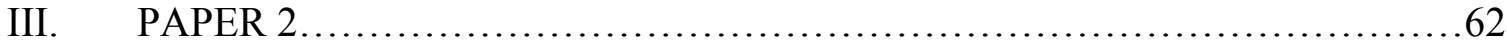

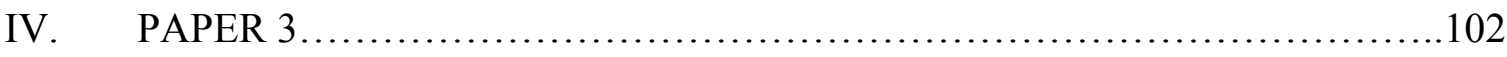

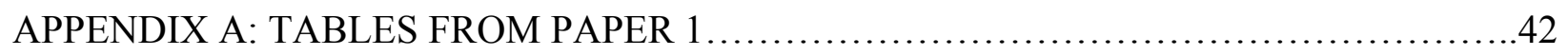

APPENDIX B: TABLES FROM PAPER 2 .......................................66

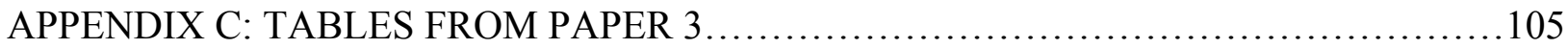




\section{DEDICATION}

This dissertation is dedicated to all of the significant adults who have supported me throughout my life and to all of the youth who still need significant adults in their lives. 


\section{ACKNOWLEDGEMENTS}

The research reported here was supported by the Institute of Education Sciences, U.S.

Department of Education, through Grant \#R305B090002 to the University of Virginia. The opinions expressed are those of the authors and do not represent views of the Institute or the U.S. Department of Education

Support for this project is also provided by the William T. Grant Foundation (Grant \# 181357). The opinions expressed are those of the authors and do not represent views of the W.T. Grant Foundation.

This research was also supported by Youth-Nex: the Center to Promote Effective Development. Youth-Nex is supported by a grant from Philip Morris USA, an Altria Company. I also acknowledge this important support. The opinions expressed are those of the authors and do not represent the official views of the sponsor.

I would also like to express sincere gratitude to:

Nancy Deutsch, the greatest most highly attuned mentor who provided me unwavering support and guidance. You always knew how to push me just the right amount without overwhelming me and I am so grateful to have been under your mentorship the past four years.

Mark Yu and Haley Johnson who worked closely with me throughout the development of this dissertation. Thank you for debating the constructs with me for hours on end, for bringing me food when I was working late, for making me socialize when I spent too much time writing, and for always, always, quelling my doubts. We rise together.

The members of my dissertation committee who provided great insight and feedback throughout this process. Thank you for all of your time and commitment to helping me strengthen my critical thinking about these constructs and improve my writing.

My parents, who might not have always understood exactly what I was doing, but always backed me $100 \%$ every single step of the way. Thank you for always believing in me and being my biggest fans.

The amazing women in my doctoral cohort who motivated, supported, and inspired me every day over the past four years. I never would have gotten here without you.

All the members of the READY lab and Curry faculty who provided me support over the past four years. 


\section{LIST OF TABLES}

TABLE

PAGE

\section{PAPER 1}

1. Social Support Excerpts................................................. 42

2. Percentages of Social Support Across VIPs......................................42

\section{PAPER 2}

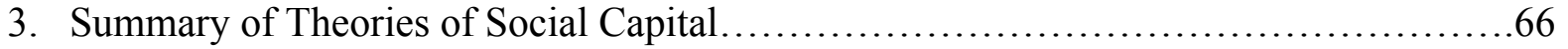

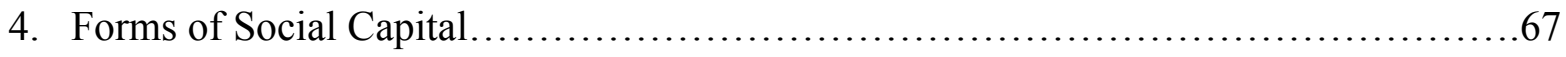

\section{PAPER 3}

5. Summary of Previous Studies of Social Capital.................................... 105

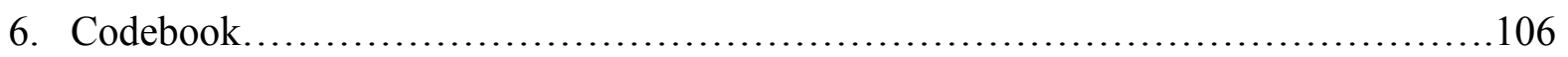




\section{LIST OF FIGURES}

FIGURE

PAGE

PAPER 3

1. Deconstructed Model of Bridging Social Capital................................... 107

2. Deconstructed Pyramid of Bonding Social Capital............................... 107 


\section{Adults as Ecological Assets for Positive Youth Development: An in Depth Examination of Social Resources \\ LINKING DOCUMENT}

An article titled "Stereotypes About Teens Can Undermine Parent's Confidence" was published on November 5, 2015 on NPR.org (Cunningham). Over 100 years after G. S. Hall characterized adolescence as a period of storm and stress, the popular narrative of adolescent behavior in America is still riddled with stereotypes about uncontrollable, risky, and delinquent behavior. The aforementioned article discussed how negative beliefs about adolescents are harmful for parents, but what is even more concerning is how these stereotypes affect our youth. Youth are often treated as if they are problems to be managed rather than future contributors to society, which has resulted in many youth growing up without the support they need to succeed (Lerner et al., 2005). In order to counter this narrative, many researchers, practitioners, and policymakers have turned to the Positive Youth Development (PYD) perspective.

The PYD perspective counters the deficit view by asserting that all youth inherently have strengths that can be maximized so that they become successful members of society (Benson, 2003). The PYD model views development as dynamic, so that problems are viewed as singular instances in a larger array of potential outcomes for youth (Lerner et al., 2005). Drawing from developmental systems and ecological theories, the PYD perspective views youth as having bidirectional interactions with the various individuals and institutions around them (Bronfenbrenner, 2006; Lerner, 2002). Moreover, when these interactions are mutually beneficial, they can promote positive developmental change in youth and lead to youth contribution back to their various ecologies (Lerner et al., 2005).

Ecological (i.e. external) assets are an important part of youth's development under the PYD perspective, in that they support healthy development within contexts in which youth are 
embedded (Benson, 2003). There are many external assets including caring neighborhoods, familial support, and relationships with non-parental adults. Current research suggests that adults may be the most important ecological assets for youths' healthy development (Theokas \& Lerner, 2006). In fact, America's Promise Alliance, a center focused on successful youth development, made encouraging relationships with caring adults the center of their initiatives for helping youth (Americaspromise.org).

Ample literature has demonstrated that youth-adult relationships (YARs) are associated with positive psychosocial and behavioral outcomes (Chang et al., 2010; Rhodes, Spencer, Keller, \& Liang, 2006; Beam, Chen, \& Greenberger, 2002). Many studies have attributed this to the important resources that adults can offer youth, namely social support and social capital (Chang et al., 2010). However, social support and social capital are both complex and multidimensional resources and the literature surrounding them are characterized by a lack of conceptual clarity. This dissertation focuses on increasing our theoretical and empirical understanding of these two resources as they apply to positive youth development.

\section{Social Support}

Cohen and Wills (1985) proposed that social support is associated with promoting wellbeing and reducing stress. Indeed, researchers have suggested that social support acts as a buffer to risk factors and promotes positive adjustment for youth (Chu, 2010; Cicognani, 2011; Kaynak, LePore, \& Kliewer, 2011). Researchers have established that there are multiple types of social support that function differently in response to different types of problems: instrumental, informational, emotional, companionship, and validation. However, the existence of multiple types of social support has created difficulties in establishing clear links between social support 
and well-being (Chu, 2010). To further complicate the picture, social support can also be provided by three different sources: parents, peers, and non-parental adults.

While much of the literature has focused on establishing links between different types of social support from parents and peers (Smetana, Campione-Barr, \& Metzger, 2006), less attention has been given to non-parental adults (Beam, Greenberger \& Chen, 2002). The research on social support and non-parental adults is very segmented, often grouping all non-parental adults into a single category. When grouping all non-parental adults, such as coaches, grandparents, and after-school programming staff into a single category, it is difficult to gain a clear picture of what types of support non-parental adults offer. The little research that does examine specific types of non-parental adults usually examines one or two types of adults (e.g. teachers) and a single type of social support (e.g. emotional). No prior study, to our knowledge, has examined all five types of social support in multiple types of non-parental adults.

Paper 1, "It's going to help me in life": Forms, Sources, and Functions of Social Support for Youth in Relationships with Non-parental Adults, presents the findings from an in-depth qualitative examination of youth's perceptions of social support in their relationships with important non-parental adults. I, with the help of my co-authors, analyzed interviews from 40 youth to examine their descriptions of social support that they received from significant adults in their lives (herein referred to as VIPs). Youth described interactions with a vide variety of VIPs including teachers, coaches, youth group leaders, grandparents, aunts, school counselors, and family friends. Three major findings emerged from the data. First, more than $80 \%$ of our youth reported receiving four or five types of social support from one adult, regardless of who that adult was (e.g., teacher, grandparent, etc.). Second, emotional, instrumental, and informational support seemed to descriptively differ depending on the adult providing the support. In other 
words, youth described emotional support from a grandparent differently than they described emotional support from a teacher. Finally, youth were able to identify benefits of social support from their VIPs, including to their academic performance, self-esteem, and identity. The results from this paper ultimately provide a fuller, nuanced, view of how social support operates in YARs.

\section{Social Capital}

Previous studies have suggested social capital is linked to several youth outcomes such as academic achievement (Kao \& Rutherford, 2007), educational attainment (White \& Glick, 2000), extracurricular participation (Glanville, Sikkink, \& Hernandez, 2008), self-concept (Thomason \& Kuperminc, 2013), substance use (Curran, 2007), dropout rates (Croninger \& Lee, 2001), and indicators of health and well being (Rosenfeld, Richman, \& Bowen, 1998). Initially, I planned on examining social capital using the same approach utilized in Paper 1 with social support, analyzing the data for presence of concrete constructs within social capital as identified within the literature. However, upon examining the very limited literature on social capital in YARs it became apparent that each study used its own definition of social capital and its own measures. While the studies of social support seemed to generally accept that there are five types of social support with somewhat uniform definitions, studies of social capital have utilized vague definitions and seem to be measuring different constructs (e.g. some economic resources, some social networks). Part of this problem seemed to stem from fact that social support is situated within the PYD framework, a framework that grew out of developmental science, whereas social capital is typically pulled from sociological or economic literature, as indicated by social capital's placement outside of the PYD frame in Figure 1. 
Therefore, in Paper 2, Conceptualizing Social Capital Within a Positive Youth

Development Framework: The Case of Youth Adult Relationships, I trace social capital from its theoretical foundations to its place in current research on YARs. I found that the complexity of social capital stemmed from three different theorists who suggested that social capital is useful at three different levels of society: individual (Bourdieu, 1985), group (Coleman, 1988), and community (Putnam, 2000). Ultimately, there were commonalities across the three theorists' definitions of social capital: connections to networks, resources, trust, and reciprocity (Enfield, 2008). Further, Putnam (2000) proposed two different types of social capital, bonding, which encompasses psychological resources, and bridging, which encompasses economic and social resources. However, most studies of social capital in YARs fail to include all three of these resources (Chang et al., 2010; Brewster \& Bowen, 2004). Whereas social capital overlaps with PYD in terms of emphasizing connections to networks, resources, trust, and reciprocity, I suggest several ways that social capital could benefit from a PYD frame: an emphasis on both bonding and bridging forms of social capital, a focus on youth agency, and a focus on bidirectional interactions. From this I propose a comprehensive definition of social capital to frame examinations of social capital in youth adult relationships: social capital is a combination of economic, social, and psychological resources, which can be accessed and exchanged through bidirectional interactions between youth and adults and institutions.

\section{Examining the Link between Social Support and Social Capital}

While previous studies have operated under different definitions of social capital and have used very different measures, findings from previous studies seemed to point towards social support as being somehow related to social capital. For example, descriptive studies of social capital found that emotional support might be a component of bonding social capital (Jarrett, 
Sullivan, and Watkins, 2005). Sullivan and Larsen (2009) found evidence of informational support and instrumental support in descriptions of bridging social capital. These findings, combined with my prior experience with qualitative descriptions of social support and my understanding of the theoretical foundations of social capital, led me to believe that social capital and social support are related, though no previous study has directly examined this relation.

Paper 3, Deconstructing Social Capital in Youth Adult Relationships presents findings from an in-depth, exploratory examination of social capital in YARs, under the definition I provide in Paper 2. I analyzed 48 youth interviews (two interviews per youth, covering two time points of data) to examine their descriptions of social capital in their relationships with a nominated significant adult and for the relationship between social capital and social support. Youth provided rich descriptions of both bonding and bridging social capital in their lives characterized by economic, social, and psychological resources. Further, both types of social capital relied on the presence of social support but also included additional social processes, which move beyond social support. Taken together, the different types of social capital represent potential pathways through which social support and other social processes (e.g. mutuality, trust) can interact to impact youth internally or externally. In addition to analyzing youth interviews, I analyzed 23 significant adult interviews to examine overlap or divergence in their descriptions of the social capital instances youth described. Adults were more likely to mirror descriptions of bonding social capital than bridging social capital. To date, no other study has conducted an in depth qualitative examination of the process of development and exchange of bonding and bridging social capital in youth-adult relationships. The results from this paper present concrete characterizations of social capital that have the potential to inform clearer definition and precision in measuring social capital in youth-adult relationships. 


\section{Conclusion}

Within the PYD movement, adults stand out as important ecological assets for youth because of the social resources they offer youth (Chang et al., 2010). Ample literature has suggested social support and social capital from non-parental adults offer benefits for youth (Chu, 2010; Chang et al., 2010). However, both sets of literature are characterized by a lack of conceptual clarity due to individual studies' focus on singular portions of these multidimensional constructs. Taken together, the body of work presented in this dissertation provides an ecological look at both social support and social capital, and the synergy between them. My findings on social support provided a nuanced understanding of how different types of social supports operate in YARs. These findings have implications for examining social support in YARs as well as holistically improving the social support in youth's lives. My proposed definition of social capital offers a uniform definition for researchers to utilize when examining YARs. Further, this definition reflects the original theories while also adding aspects of PYD. The findings from my exploratory examination of social capital provide support for youth accessing and exchanging social capital through bi-directional interactions with adults. Further, the findings of how social capital and social support are related can lead to a better understanding of how to measure social capital in YARs. Overall, through this work I aim to provide precision and clarity to these two important social resources so that researchers and practitioners may better understand how to provide support to youth. 


\section{References}

Americas Promise Alliance (2015). The 5 Promises. Retrieved from http://www.americaspromise.org/promises.

Beam, M., Chen, C., \& Greenberger, E. (2002). The nature of adolescents' relationships with their "very important" nonparental adults. American Journal of Community Psychology, $30(2), 305-325$.

Benson, P. L. (2003). Developmental assets and asset-building community: Conceptual and empirical foundations. In R. M. Lerner \& P. L. Benson (Eds.), Developmental assets and asset-building communities: Implications for research, policy, and practice (pp. 19-43). New York: Kluwer Academic/Plenum.

Brewster, A. B., \& Bowen, G. L. (2004). Teacher support and the school engagement of latino middle and high school students at risk of school failure. Child and Adolescent Social Work Journal, 21(1), 47-67.

Bronfenbrenner, U., \& Morris, P. A. (2006). The bioecological model of human development. In R. M. Lerner (Ed.), Handbook of child psychology: Vol. 1. Theoretical models of human development (6th ed.). Hoboken, NJ: Wiley. Editors-in-chief: W. Damon \& R. M. Lerner.

Bourdieu P. (1985). The forms of capital. In J. G. Richardson (Ed.), Handbook of Theory and Research for the Sociology of Education, (p. 241-58). New York: Greenwood.

Chang, E. S., Greenberger, E., Chen, C., Heckhausen, J. and Farruggia, S. P. (2010), Nonparental Adults as Social Resources in the Transition to Adulthood. Journal of Research on Adolescence, 20, 1065-1082. doi: 10.1111/j.1532-7795.2010.00662.x 
Chu, P. S., Saucier, D.A. \& Hafner, E. (2010). Meta-analysis of the relationships between social support and well-being in children and adolescents. Journal of Social and Clinical Psychology, 29(6), 624-645.

Cicognani, E. (2011). Coping Strategies With Minor Stressors in Adolescence: Relationships With Social Support, Self-Efficacy, and Psychological Well-Being. Journal of Applied Social Psychology, 41(3), 559-578. doi: 10.1111/j.1559-1816.2011.00726.x/full

Cohen, S. \& Wills T A. (1985). Stress, social support, and the buffering hypothesis. Psychological Bulletin, 98:310-57.

Coleman, J. S. (1988). Social capital in the creation of human capital. American Journal of Sociology, 94, 95-120.

Croninger, R., \& Lee, V. (2001). Social capital and dropping out of high school: Benefits to atrisk students of teachers' support and guidance. Teachers College Record, 103.

Cunningham, A. (2015, November 5). Stereotypes About Teens Can Undermine Parents Confidence. Retrieved from http://www.npr.org/sections/healthshots/2015/11/05/454598615/stereotypes-about-teens-can-undermine-parents-confidence

Curran, E. (2007). The relationship between social capital and substance use by high school students. Journal of Alcohol \& Drug Education, 51, 59-73.

Enfield, R. (2008). Social capital and implications for positive youth development. Retrieved from http://4h.ucanr.edu/files/1225.pdf

Glanville, J., Sikkink, D., \& Hernandez, E. (2008). Religious involvement and educational outcomes: The role of social capital and extracurricular participation. The Sociological Quarterly, 49, 105-137.

Jarrett, R. L., Sullivan, P. J., \& Watkins, N. D. (2005). Developing social capital through 
participation in organized youth programs: Qualitative insights from three programs. Journal of Community Psychology, 33(1), 41-55.

Kao, G., \& Rutherford, L. (2007). Does social capital still matter? Immigrant minority disadvantage in school-specific social capital and its effects on academic achievement. Sociological Perspective, 50, 27-52.

Kaynak, O., Lepore, S.J., \& Kliewer, W. (2011) Social moderation of the relation between community violence exposure and depressive symptoms in an urban adolescent sample. Journal of Social and Clinical Psychology, 30, 250-269.

Lerner, R. M. (2002). Concepts and theories of human development (3rd ed.). Mahwah, NJ: Lawrence Erlbaum.

Lerner, R. M., \& Lerner, J. V., Almerigi, J., \& Theokas, C. (2005). Positive youth development. Journal of Early Adolescence, 25(1), 1-144.

Puntnam, R. (2000). Bowling alone: The collapse and revival of American community. New York: Simon and Schuster.

Rhodes, J., Spencer, R., Keller, T., \& Liang, B. (2006). A model for the influence of mentoring relationships on youth development. Journal of Community Psychology, 34, 691-701.

Rosenfeld, L. B., Richman, J. M., \& Bowen, G. L. (1998). Low social support among at-risk adolescents. Social Work in Education, 20, 245-260.

Smentana, J. G., Campione-Barr, N., \& Metzger, A. (2006). Adolescent development in interpersonal and societal context. Annual Review of Psychology, 57, 255-284.

Sullivan, P. J., \& Larson, R. W. (2009). Connecting youth to high-resource adults: Lessons from effective youth programs. Journal of Adolescent Research. 
Theokas, C., \& Lerner, R. M. (2006). Observed ecological assets in families, schools, and neighborhoods: Conceptualization, measurement, and relations with positive and negative developmental outcomes. Applied Developmental Science, 10, 61-74.

Thomason, J. D., \& Kuperminc, G. (2014). Cool Girls, Inc. and Self-Concept The Role of Social Capital. The Journal of Early Adolescence, 34(6), 816-836.

White, M. J., \& Glick, J. E. (2000). Generation status, social capital, and the routes out of high school. Sociological Forum, 15, 671-691. doi:10.1023/A:1007515100190 
"It's going to help me in life": Forms, sources, and functions of social support for youth in relationships with non-parental adults

\author{
Shannon M. Varga \\ Haley E. Johnson \\ Mark Vincent B. Yu \\ Nancy L. Deutsch \\ University of Virginia
}

Valerie A. Futch Ehrlich

Center for Creative Leadership 


\begin{abstract}
Social Support is associated with positive physical and psychological health outcomes for youth. We took an ecological approach to examining the forms, sources, and functions of social support youth receive from non-parental adults. Data for this study comes from interviews of 40 youth participating in a mixed-methods longitudinal study of youth-adult relationships. Analyses revealed 1) different types of adults had the capacity to provide all types of support, and were likely to provide overlapping supports. 2) Emotional, informational, and instrumental support qualitatively differed depending on the adult's role (e.g. teacher), while companionship and validation was consistent across adults. 3) Youth were able to identify benefits attached to the social support received from important adults. Our findings contribute to a more nuanced understanding of social support received from important adults and call for fuller assessments of social support in youths lives so we may better meet their developmental needs.
\end{abstract}




\section{Introduction}

Social support, which can broadly be considered feeling relationally and emotionally supported by others (Cobb, 1976), has been associated with positive physical and psychological health outcomes for adolescents (Cohen \& Wills, 1985). Social support can occur in various forms (e.g. informational, emotional) as well as come from various sources (e.g. parents, peers). Many studies have found that sources of social support vary across adolescence, with younger adolescents reporting more support from parents and older adolescents reporting higher levels of support from peers (Bokhorst, Sumter, \& Westenberg, 2010). Although much research on social support in adolescence focuses on the role of parents and peers, there is a third source of social support that is under researched- non-parental adults (e.g. teachers, coaches, after school program staff, family members; Chu, 2010).

It has been demonstrated that adolescents' relationships with non-parental adults are important for positive youth development (Chang, 2010) and have been associated with positive outcomes such as behavioral and psychosocial well-being (Dubois \& Silverthorn, 2005). Additionally, over $70 \%$ of adolescents report having some kind of "very important" non-parental adult in their lives (Dubois \& Silvernthorn, 2005; Beam, Chen, \& Greenberger, 2002), making the presence of such support normative for the majority of youth. Despite the importance and prevalence of youth-adult relationships (YARs), researchers still have relatively little understanding of what types of social support different types of adults (e.g. coaches vs. teachers) are offering youth. This gap can be attributed to the segmented nature of literature on YARs; studies often examine only a single type of adult, such as teachers, (Zeldin, Larson, Camino, \& O'Connor 2005). In those studies that do examine multiple types of adults researchers tend to 
combine adults into broad categories (e.g. kin vs. non-kin; Chang et al., 2010), making comparisons between different types of non-parental adults difficult.

Understanding variation in YARs across types of adults and types of social support offered can help us take more targeted approaches to engendering social support for youth. This study seeks to address this goal by exploring whether and how different non-parental adults serve as sources for different types of social support.

\section{Literature Review}

\section{Social Support}

The presence of social support has been associated with physical and psychological health (Cohen \& Wills, 1985). For adolescents, social support has been found to buffer the effects of risk factors as well as promote positive adjustment (Chu, 2010; Cicognani, 2011; Kaynak, LePore, \& Kliewer, 2011). It has been established that there are different types of social support which function differently in response to various types of problems (Wills \& Shinar, 2000). Wills and Shinar (2000) identified and defined five specific types of social support, all of which can be provided by multiple sources. Instrumental support is the provision of concrete, practical assistance, such as providing transportation or helping with chores. It has been suggested that instrumental support is beneficial for youth because it involves practical problem solving and allows them to relax (Wills \& Shinar, 2000). Informational support is the provision of knowledge, advice, or guidance for youth, such as providing information about applying to college. Emotional support involves being available and listening to youth when they are having problems, while also providing indications of caring, acceptance, empathy, trust, and love. Emotional support has been linked to increases in self-esteem and decreases in anxiety and depression (Furman \& Buhrmester, 1992). Companionship support involves being available for 
participating in social and leisure activities. Validation support is process of providing positive confirmation about the appropriateness of youth's behaviors; it has also been called feedback or social comparison. Validation support has been linked to decreases in behavioral issues and increases in feelings of belongingness (Smetana, Campione-Barr, \& Metzger, 2006). Despite the multitude of research on the general benefits of social support for youth, researchers have still not identified which types of social support are most critical for adolescents (Chu, 2010). In addition to the multiple types of social support, researchers have identified three different sources of social support for youth: parents, peers, and non-parental adults (Chang, 2010; Chu et al., 2010).

\section{Sources of Social Support}

Parents and peers. The nature and quality of parent and peer support for adolescents has been heavily researched, as parents and peers are considered major sources of social support for adolescents (Chang, 2010). Traditionally, parents have been found to be important providers of informational support for long-term issues for youth, such as career choices (Harris, 1998). Additionally, emotional support from parents has been linked to higher self-esteem, psychosocial competence, identity development, and lower depression for adolescents (Smetana, CampioneBarr, \& Metzger, 2006). However, it has been empirically established that feelings of emotional support from, warmth, and closeness to parents typically decline for youth during adolescence (Smetana, Campione-Barr, \& Metzger, 2006; Buhrmester \& Furman, 1987), suggesting that adolescents turn elsewhere for support. For example, as youth age, they report higher levels of social support from peers (Bokhorst, Sumter, \& Westenber, 2010; Furman \& Buhrmester, 1992). Peers have been found to be a source of validation support or social comparison for youth during a time of identity exploration (Brown, 2004). In addition, researchers find that peers provide 
companionship and emotional support, which has been associated with psychosocial adjustment and feelings of belonging for youth (Furman \& Buhrmester, 1992). While there is general consensus about the different types of social support offered by parents and peers, the types of social support provided by non-parental adults is less understood (Chang, 2010; Smetana, Campione-Barr, \& Metzger, 2006).

Non-parental adults. While relationships with non-parental adults can come in the form of formal mentoring relationships established through mentoring programs, youth are more likely to have relationships with non-parental adults who they interact with in their daily settings and who become significant over time, sometimes referred to as natural mentors. These relationships are naturally occurring, meaning that they develop as a part of the normative experience of growing up (Beam, Greenberger \& Chen, 2002). It is important to understand these relationships because all youth have access to non-parental adults. In general, non-parental adults are seen as offering social support somewhere between parents and peers in that they can provide both the structure found in relationships with parents and the companionship found in relationships with peers (Chang, 2010; Beam, Greenberger \& Chen, 2002). In regards to social support for youth, teachers are by far the most researched non-parental adults.

Teachers. Although adolescents spend a lot of time with teachers, Dubois and Silverthorne (2005) found that only $25 \%$ of their adolescent sample nominated teachers as natural mentors. In general, social support from school-affiliated adults has been linked to greater engagement and satisfaction with school (Demaray, 2002; Somers et al., 2008; Kalil \& Ziol-Guest, 2008). However, studies vary in describing the types of support offered by teachers. Richman, Rosenfield, and Bowen (1998) found that high school students received technical appreciation (most akin to validation) from their teachers. Another study found that adolescents 
reported teachers provided more instances of informational support than both parents and peers (Malecki \& Demaray, 2003). However, the same study showed that emotional support from teachers was the sole predictor of a student's social skills and academic competence. As a result of the complicated picture of teacher social support the authors stress, "that teachers should be aware of the type of support they are providing their students and should seek to strike a balance between those types of support, particularly informational and emotional support" (Malecki \& Demaray, 2003, p. 248). Additionally, as youth become older, their perceptions of teacher social support decreases (Bokhorst et al., 2010), further illuminating the need to understand social support processes specifically within teacher-student relationships.

Kin. It has been suggested that family, aside from peers, represent the largest portion of adolescent's social networks, and that extended family members would be the most naturally occurring sources of support for youth (Tracy \& Biegel, 1994; Dolan 2006). Indeed, Dubois and Silverthorne (2005) found that non-parental kin were the type of non-parental adult who was most likely to be nominated by youth as a natural mentor. These family members included older siblings, grandparents, and aunts and uncles. Similar to the literature on social support from teachers, research has identified a variety of types of social support provided by non-parental kin. One study found that families provided unconditional regard and information on an individual's self-worth (validation support; Cutrona, 2000). On the other hand, family members were found to be the most durable and dependable source of instrumental support (Tracy \& Biegal, 1994; Dolan, 2006). These mixed findings are likely due to the little research on adolescents' relationships with kin other than parents and siblings (Smetana, Campione-Barr, \& Metzger, 2006). Given the evidence that extended family members are most likely to be nominated as 
natural mentors for youth, more research needs to be done to understand the social support being offered by them.

Non-kin (excluding teachers). This broad category can include formal mentors, coaches, neighbors, after-school program staff, religious leaders, and any other adult who is neither a family member nor a teacher. Although a wide range of roles fall into this category the literature often groups them together into a singular category in order to contrast them with teachers, parents, and peers (Chang et al., 2010; Greenberger et al., 1998). It is unsurprising, then, that the literature has many different assertions for what type of support these adults offer youth. One study found that non-kin VIPs were important sources of social capital for youth (Chang et al., 2010). Another study found that non-kin VIPs were important sources of emotional support for youth (Haddad et al., 2011). In a study of after-school programs, Hirsch and colleagues (2000) found that after-school program staff offered validation and emotional support to youth, which improved their self-esteem as well as allowed them to feel more comfortable at the program. It is likely that non-kin as a group can offer all types of social support but it is also possible that certain types of adults offer different types of social support for youth. Breaking down the category of non-kin into more specific roles or settings can help move towards what types of social support are most critical from youth, and where they can get it from.

While some researchers suggest that adults in certain roles are more likely to provide certain types of support for youth (e.g. teachers offer informational/instrumental; Furman \& Buhrmester, 1985), their conclusions are often limited by a lack of direct comparisons between different adults. In addition, Chang (2010) asserts that previous studies are also limited by crosssectional designs and retrospective reports of relationships (Chang, 2010). An in-depth study on types of social support across different types of youth-adult relationships is needed in order to 
further understand social support in youths' relationships with non-parental adults. Further, a meta-analysis on the relation between social support and adolescent well being found that youth's own perceptions of social support were more strongly associated with well-being than any other type of measure (e.g. actual presence of social support; Chu, 2010). Therefore, we are taking an in depth qualitative approach to understanding social support from the youth perspective through interviews with youth who are currently in relationships with non-parental adults.

\section{This Study}

This paper uses youth interviews from one time point of a longitudinal study of youthadult relationships to examine youth's relationships with multiple types of non-parental VIPs and the social support offered by those VIPs. Based on previous literature, we explored three research questions:

1. What forms of social support do youth report receiving from different types of adults?

2. In what ways, if at all, does the content of each type of social support vary by source (e.g., do youth describe the emotional support they get from teachers as different from emotional support they get from coaches)?

3. What functions do youth perceive for each type of social support?

\section{Methods}

This paper draws on data from a larger mixed methods, longitudinal study of youth-adult relationships. Adolescents (ages 12-17; N=289) were recruited from a mid-sized, mid-Atlantic city through local youth programs, schools, and community settings. A subsample of 41 youth was then purposively selected to represent a variety of psychometric properties (e.g. attachment 
style) and volume of adult relationships. The majority of the subsample is white (80\%) and female (54\%). The subsample will complete six interviews across three and half years. At each time point the interviewee is provided a definition of a significant adult and then asked, based on that definition, whether or not s/he currently has a significant adult (see definition below; herein referred to VIP), if so, who that person is, and a series of questions about their relationship.

\section{Sample}

The current study examines data from the 40 youth who named a VIP at the Time 1 interview. Only one male participant, age 14, did not nominate a VIP at Time 1 . The sample for this paper includes 22 females and 19 males. Seventy-five percent identified as white, $10 \%$ of the sample identified as African American, and the remaining 5\% identified as Latino or mixed-race. At the time of the first interview, the participants ranged in ages from 12-17 (mean = 14.58) and about $17 \%$ were eligible for free or reduced price lunch.

\section{Interview protocol}

The interview protocol was developed by the research team and focused on understanding youth's relationships with significant non-parental adults. Based on earlier studies of non-parental youth-adult relationships (Hirsch, Deutsch, \& DuBois, 2011), significant adults (VIPs) were defined as “...persons you count on and that are there for you, believe in and care deeply about you, inspire you to do your best, and influence what you do and the choices you make." The protocol also includes a series of follow up questions about the youth's relationship with the VIP, including questions specifically aimed assessing and exploring the presence and content of different sources of social support:

- Do you ever talk about personal stuff with [VIP]? (emotional support) 
- Does [VIP] help you with your homework? Or does he/she help you with other things? (instrumental support)

- Does [VIP] ever give you advice? How often? What kinds of advice? (informational support)

- Does being with [VIP] make you feel better about yourself? In what ways? (validation support)

- What do you usually do together or talk about? (companionship support)

\section{Analyses}

As part of the larger project, the research team developed thematic codes (Yin, 2010) encompassing the goals of the study, including social support. Once the themes were developed, six researchers coded the transcripts using Dedoose version 6.1.18, a cloud based mixed methods data analysis application. The entire team met weekly to address coding questions and to ensure reliability. Two coders were assigned to every transcript and after both coders independently coded a transcript, the two coders compared the codes and reconciled any discrepancies. Discrepancies which the coders could not reconcile or which they had questions about were brought to the larger group meeting and discussed and reconciled by the entire research team.

After all 40 transcripts were reconciled, the first and second authors then sub-coded excerpts of social support for the five types of support. We coded for companionship, emotional, instrumental, informational, and validation based on Wills and Shinar's (2000) definitions (see table 1 for examples of this coding in our data). The two authors coded independently, meeting frequently, to ensure adherence to Wills and Shinar's definition. Once the 40 transcripts were sub-coded, the authors reconciled the transcripts. Youth were then categorized based on their VIP's role, both in specific terms (grandma, cross country coach) and broad terms (teachers, 
family, non-familial excluding teachers). To examine the first research question, we used Dedoose's capacities for quantitative analysis of qualitative data to examine the prevalence of the different types of social support across the different VIP roles. We were able to view the percentage of excerpts coded for each type of social support by VIP type (percentages were normalized to control for unequal number of VIP types). To answer research question two, the first two authors qualitatively compared instances of instrumental support to examine if instrumental support differed by VIP roles. This was an iterative, communicative process between the two coders. The same process was completed for the other four sources of social support. For research question three, the authors qualitatively examined each transcript for instances of youth describing social support impacting outcomes previously identified to be relevant in the literature such as self-esteem, identity, and academic achievement, as well as any emerging outcomes.

[Insert table 1 here]

\section{Findings}

Of the VIPs youth nominated, 28.6\% were from school settings (mostly teachers and coaches), $25.7 \%$ from family settings, $8.6 \%$ from after-school settings, $5.7 \%$ from neighborhood settings, $2.9 \%$ from community settings (e.g. church), and $28.6 \%$ from other settings (e.g., family friends).

\section{Question 1: Forms of social support across adults}

Across all the participants in our study, youth reported receiving all five types of social support in relatively equal proportions, with three quarters of youth reporting receiving four or five types of support from their VIP. This finding suggests that all types of VIPs (e.g. teachers, 
neighbors) are capable of providing multiple types of social support to youth. It also indicates that youth get multiple types of support from adults who they see as important to them.

The different types of social support occurred fairly equally, with some small differences, across the sample as a whole, there were some variations in the prevalence of different types of social support that different adults provided (See table 2). Non-kin, which consisted of mostly family friends and coaches, had the most instances of emotional and informational support. Teachers, offered the most instrumental support, and had the most instances of companionship and validation, though only slightly more than family members.

[Insert table 2 here]

\section{Question 2: Differences in social support by source}

In addition to knowing whether adults differed in the types of support provided, we were also interested in whether different types of adults provided the same type of support in different ways; that is, does emotional support from a teacher differ from emotional support from a family friend, coach, family member, etc. We examined the data within social support type to see if there were qualitative differences in the nature of support provided across types of adults. We found that for certain types of support, youth's descriptions of the support differed depending on the type of adult providing it. In addition, we found differences in youth vs. adult initiation across supports; youth initiation refers to the youth seeking out support whereas adult initiation refers to the adult openly giving the support without prompting.

Instrumental. Teachers, coaches, and youth group leaders typically provided instrumental support within specific domains related to their roles, such as assistance with homework or tasks related to their subject area for teachers or assistance with specific sports skills for coaches. For example, Bob, an older high school male, described going to his Spanish 
teacher for instrumental support related to that teacher's class: "I either go in and talk to him in the mornings to get extra help, or after I get a quiz back or something, he'll go over it with me. And he'll just tell me what I could do to study better, to learn more." Another high school aged participant, Missy, described various ways in which her coach's feedback helped improve her swimming technique, "to do underwater kicks and to just like make sure my arms are extended in butterfly...." While Missy's relationship with her coach was solely based around swimming, she explained that she felt this support was important. For Missy, being a swimmer appears to be a central part of her identity, so it is not surprising that instrumental support in improving swimming would be important to her.

Perhaps not surprisingly, family friends and relatives offered a wider variety of instrumental supports, from taking care of the youth when the youth's parents were away to getting the youth involved with community work. For example, Skye, a first year high school student, described how her family friend helps her “...if my parents ever have to go somewhere or something like that the we're over there and spend the night even if it's on a school night." Alicia, an older high school student, discussed how her grandmother helped her in multiple academic subjects: "she has looked over an English paper before because she's a professor, just to help edit it, and she is also almost fluent in French, so I take French, so sometimes I ask her to help me." Overall, it appeared that youth most often initiated specific instrumental support, as seen above with Bob asking his Spanish teacher for help and Alicia asking her grandmother for help with homework.

Emotional. Different types of VIPs appear to have different ways of offering emotional support. Family friends, family members, and school counselors offer youth nonjudgmental spaces to discuss their dilemmas and then go on to offer youth advice or techniques for solving 
their problems. For example, Alicia said if she needed to talk about a personal problem with her grandmother "She would be completely fine with it and offer whatever advice she could." Lizzy also said of her grandmother, "I call her and talk to her about any problems that I have, so she helps me a lot." Swagballer, a middle school student, discussed how her counselor helped her deal with expressing problems "I usually bottle it up and then I get mad and then I start going crazy. Yeah. She kind of taught me how to be calm and express what you're feeling instead of bottling it up." In another example with a school counselor, MollyHooper said "Like she'll help me come up with ways to distract myself or will just tell me that it's not important what other people think." It was not clear whether adults or youth initiated discussions of personal matters. However, discussions with family friends, family members, and school counselors were almost always followed by seemingly unsolicited, but not necessarily unwelcome, solutions from the adults, which overlaps with instrumental or informational support. The emotional support provided by teachers, on the other hand, appeared to be a more literal representation of emotional support under the Wills and Shinar (2000) definition.

Teachers who offered emotional support offered an open and nonjudgmental space for youth to discuss personal topics and demonstrated a feeling of caring for youth. This is reflected in several interviews. Connor, an older high school boy, for example, said, "it's nice to be able to talk to - just be able to have a free conversation with someone like they're a peer." Skylar said, "it's nice to know that a teacher cares and wants other students to know more and be the best that they can be with their knowledge." Whereas other types of VIPs often moved from providing support to helping solve the problem, in the realm of emotional support teachers often stopped at offering the youth someone to listen to their problems and empathize with them. 
Informational. Informational support followed a similar trend to instrumental support with teachers, coaches, and youth group leaders typically providing information within their topic area. For example, Michael a middle school student explained that his teacher gives him advice “... if you want to like, I don’t know, do well in his class or something. Not like personal advice, just like school-work related." Connor echoes this when describing what advice his teacher has given him: "he just makes sure you ration your time. Make sure you know what you're going to do when so it doesn't all just snowball out of control. Make sure you stay on top. It's a class...." Coaches typically offered advice to improve athletic performance. For example, Bartholomew said his coach gave him advice on, "like running form, how to be more efficient with your stride, more stretches, that kind of stuff." Carrie, a middle school participant, describes her youth group leader giving her situational advice: "like if someone comes up and just says, like cusses you off, instead of cussing right back at them, to just say 'hey whoa' and to just handle it in a Christian way." In all of these cases, the adults are providing guidance to the youth in how to better act in a particular role, whether the role is a student, an athlete, or follower of a religious doctrine. In addition, adult initiation, rather than the youth seeking out advice mostly drove informational support from these VIPs. It is important to note that many teachers, coaches, and youth group leaders in our study offered additional supports to students, but informational support was mostly domain specific.

Family friends offered advice in multiple areas, ranging from school to personal issues. Colt, who is in high school, described the advice he receives from his VIPs (a married couple): "I mean because we see them so often, it'd be just on anything that's happening whether it's schoolwork or if a basketball or soccer game I have coming up or just anything." Skye, who is 
the only girl in her immediate family, turns to a family friend who has multiple daughters for advice:

...we have an $8^{\text {th }}$ grade formal and so there is a lot of drama that would go along with that and I'm not like- I just don't like drama- so she says like- "oh well this is how it's probably gonna play out and you can just wait it out and just kind of see how it goes. People will know that you're not into drama like that and so they'll just kind of leave you out of it," and stuff like that.

Family members offered general life advice, often stemming from personal experience. Nicole's aunt told her “don't do nothing stupid, follow directions and all that, and don't let nobody tell me what to do and all that stuff." Another participant, Rachel discussed how her aunt typically helped her through situations by giving her examples of what she would do in her position. Rachel later states appreciation for her aunt's perspective. Red, a middle school student, explained that his grandmother offers personal stories in order to support him “...sometimes it is good advice for school. It's like if I'm having an annoying teacher she tells a funny story about what she did or whatever, so it helps me get past the annoyance at the teacher." Advice from family friends and family members tended to be mixed in terms of youth or adult initiation. Youth most frequently initiated for advice on particular situations in their lives, as seen in Red's interview, whereas adults would often offer unsolicited general life advice, as was seen with Nicole's aunt.

Validation. Validation did not differ in nature across different types of adults. However, we found evidence of two different processes of validation in youth's discussions of this kind of social support. In the first process, the adult complimented the youth, which youth reported as boosting their self-esteem. For example, DrewBrees a middle school male said his grandfather 
makes him feel better about himself because "he always is saying I'm turning into a great guy and jokes around a lot with me." Another example of this process was presented earlier when Connor described how his teacher's compliments on his test performance made him feel good about himself. The second process occurred when adults offered some sort of indication to youth that their thoughts, feelings, or actions were valid, which helped them feel more comfortable with being themselves. Michael discussed how his teacher allowed him to joke around in class and how important he felt that was:

Because I mean I don't talk or get into very many like- I don't know like I don't really talk to that many adults. Like he's just like that teacher that's nice and that I like, and how he was kind of tolerant of me back then, and that really stood out. Because yeah, I was either that annoying kid that was in class, that the teacher wouldn't like, or that funny annoying kid...

Rachel also described this process when discussing her aunt, “well again with like- I don't feel like she judges me, and she doesn't like put down what I'm saying or it's like wrong to feel this way or whatever. She just like understands and tries to help me.” Both of these processes were found across adults and both were important to youth in different ways, the first for boosting self-esteem and the second for affirming their thoughts, feelings, or actions. It seemed that adults often initiated compliments but youth might seek out adults they already knew accepted them in order to seek validation for thoughts, feelings, or actions.

Companionship. Companionship did not differ in nature across different types of adults. Instances of companionship were often found in response to the general question of "what is your relationship like with VIP?" Claire, for example, alludes to companionship in her descriptions of grandmother: "Well she's really fun to be around and you can easily talk to her 
and she's not afraid to like, if you see something, to laugh at her, like even if it's about her and she's easy to get along with." Companionship was also seen in response to more specific questions about what youth do with VIPs and why they feel close to VIPs, such as when Michael described conversations with his teacher: "Kind of just like joke around. So make jokes or do funny, humorous things." Katherine referenced companionship when describing why she feels close to her VIP, a family friend: "well, we joke around a lot, and we do activities together, like get pedicures or cook and stuff like that, so that's fun." Across all types of VIPs, companionship was paired with humor and general references to enjoying the VIP's company. Additionally, companionship appeared to stem from shared interests such as sports, playing games, and listening to music.

\section{Question 3: Perceived Functions of Social Support}

Youth were able to describe perceived impacts of the different types of social support that they were receiving. This largely resulted from follow up questions in the interview protocol. After youth reported receiving a certain type of support from VIPs, interviewers asked if the youth felt the support was important, and if so why. Youth most often felt the support they were receiving was important and then were able to explain how they felt most supports affected them.

Youth often reported that the validation they received from their VIPs improved their self-esteem or reinforced their identity, as was seen in examples reported above, such as when Michael felt more comfortable in his identity as a "joker" when his VIP did not chastise him for joking in class as other teachers did. A further example comes from Scooter who described how his VIP helped him feel better about himself by saying:

....in different ways. Like she always calls me like Awesome [Scooter] and things like that, so it like makes me - it just like boosts my self-esteem. And she also understands 
the things that I'm trying to say. Like when we're in group conversations.... if I'm saying something kind of out of the ordinary, she'll understand and try to explain it. Scooter's pastor provided compliments and positive confirmation about his behaviors to other people in group conversations. In another example, McMolnakerson, a high school male described why he felt close to his teacher by saying, "I'm one of the better students in the class, like I do all my work and I always pay attention and he's just nicer to me. He'll give me like bigger projects and he'll let me do stuff that he won't let other kids do." He goes on to say behavior like this lets him know that his VIP respects him. While McMolnakerson's identity as a good student might have been in tact before he met his VIP, his VIP's preferential treatment serves as a constant external affirmation to his internal beliefs.

Instrumental support from VIPs was often described as having an impact on academic achievement. For example, Swagballer described how her VIP helped her improve her grades: ...[VIP] actually helped me. In algebra, I had a D. She helped me bring it up.... to a high B by the end of the year..... I would go during the last 15, 20 minutes of algebra to her office. We would just talk about what we learned before that class and then she would help me learn what we were doing that class, so I know.

Another participant, Colt, talked about ongoing improvement with his writing: "Yeah, [VIP] helps me a lot just because I think she majored in English so she, in like writing, I'm not that good of a writer, so she'll always help me in that. So, she's helped me a lot over the past couple years just because writing is getting more and more a big part of school." VIPs have also provided instrumental support in helping youth accomplish personal endeavors such as fixing cars, improving in sports, and getting involved in community service. 
Informational support was often described as integral to improving specific skills, as we saw earlier with coaches giving advice for bettering athletic performance and teachers giving advice for excelling in the classroom. Youth also reported more general life advice to be important as well. For example, Lucy said her family friend's life lessons are important “...because it's going to help me in life and she always encourages me to do my best. Because sometimes I'm not really motivated but she always tell me like how if I don't get motivated then I'm not going to have a successful life." She perceived these life lessons to be helpful to her long-term character development.

Youth in our study did not consistently link companionship and emotional support (without the addition of instrumental or informational support) to outcomes. However, both of those supports appeared to function as tools that allowed youth to feel closer to adults; emotional support and companionship were present in conversations about why youth felt close to VIPs. Companionship often came in the form of shared experience or interests, "Well actually she she's a vegetarian, and she kind of introduced the whole thing to me. And that makes me kind of feel close to her." Emotional support manifested in the adult being open, "she like is very open about talking about things in my life and her life. So I feel like I can really talk to her about anything, and she's just like comfortable." While the youth did not discuss improvements or changes in any quantifiable sense, these supports, by strengthening the relationship between the youth and the adult, likely helped the youth be more receptive of the other supports.

\section{Discussion}

We found that all types of VIPs in our study were providing multiple types of support, that certain supports differed depending on the adult providing the support, and that youth were able to identify benefits of social support. Our first finding suggests that previous studies are 
likely uncovering separate pieces of the larger picture of how specific types of social support function in YARs. Like previous studies, we found that teachers offer validation (Richman, Rosenfield, and Bowen, 1998) and informational support (Malecki \& Demaray, 2003). However, counter to Bokhorst and colleagues (2010) finding that perceptions of teacher social support declines as students' age, we found similar descriptions of teacher emotional support for middle and high school students. This is important given Malecki and Demarary's (2003) findings that teacher emotional support is strongly associated with student's social skills and academic competence. Our findings suggest teachers can provide emotional support as youth age and it does not need to descriptively differ by age group.

When looking within types of social support offered by different types of adults, we found that emotional, informational, and instrumental support might look different depending on the type of adult providing it. This has implications for examining and understanding social support. If the same type of social support can function differently depending on the VIP providing it, more work needs to be conducted on singular types of support from various types of VIPs, first for replication but second for points of intervention in youth's lives. For emotional support, youth's descriptions suggest that teachers need only offer a nonjudgmental space for youth to share their problems whereas they receive problem solving advice from family friends, family, and advisors. Given that emotional support from different sources is linked to different outcomes for youth, such as psychosocial competence from family (Smetana, Campione-Barr, \& Metzger, 2006) and academic competence from teachers (Malecki \& Demaray, 2003), it is then understandable that those adults differ in their approach to emotional support. Though no previous study has reported this. Moreover, it is important to understand how different sources 
vary in their approach to offering certain types of social support so that we can better understand how to better provide social support to youth who are lacking it.

A secondary finding when we looked in-depth at how adults provided social support is that there were differences in youth and adult initiation across supports. Youth were more likely to seek out instrumental and informational support for specific reasons. Finding evidence of youth initiation is important because many studies of social support only assess the presence of social support, which perpetuates the idea that youth are passive receivers of support. Rather, our findings support the positive youth development theory assertion that youth are active agents in their own development as they are actively seeking out certain types of social supports (Lerner, 2002).

Finally, with regard to youth outcomes, we found that youth were able to perceive and describe benefits of different types of social support. First, our findings align with previous literature as youth described benefits in the same direction that previous literature has asserted; validation was important for self-esteem and identity (Cutrona, 2000), instrumental support was described as important to academic competence (Tracy \& Biegal, 1994; Dolan, 2006), and informational support was related to improving skills (Wyndol, \& Buhrmester, 1985). Informational support was also revealed to have implications for potential long-term benefits for character development. While emotional support and companionship were not explicitly linked to any outcome both seemed to be important to strengthening youths' relationships with adults and allowed them to be more open to other types of support. This is somewhat in line with Hirsch and colleagues (2000) findings on the benefits of emotional support from program staff at after-school organization. In their study, emotional support from staff allowed youth to feel more comfortable with the staff and at the program. We could additionally suggest that emotional 
support and companionship may strengthen youth's relationships with adults by fostering mutuality, empathy, and trust and, thereby, increasing the likelihood of the relationship having positive effect on youth development, per Rhodes' (2002) model of mentoring's effects.

Ultimately our findings have provided a nuanced view of the way different types of social support are perceived by youth and how they differ between different types of adults. This calls for future studies to take a more ecological view of social support in youths lives, that is examining how youth are interacting with social support sources in multiple different contexts (e.g. family, school, after-school; Bronfenbrenner, 2006). This will allow us to have a fuller understanding of the social support that youth are missing, and how to better meet their needs.

\section{Limitations}

All studies have limitations. One limitation of our study is that we only know about those adults who youth deem to be significant. Thus, an additional interpretation for our findings from question one is that adults that rise to the level of "significant" in youth's eyes are likely providing more than one support to youth. Given that this study did not include descriptions of adults who the youth do not feel close to, we could not make this assertion. Future studies should examine this. Some of our findings are heavily tied to roles, such as teachers and coaches providing informational and instrumental support primarily in their areas of expertise. It is possible that youth's expectations of roles are related to how they perceive social support; that is, for example youth have limited expectations for what social support a teacher would provide to them as it is not typically within their role. Future studies should assess expectations of support from various sources based on roles and to what extent, if any, those expectations are related to youth's perceptions of social support. Further, our study is limited in that we only examine one time point from a longitudinal study. Future studies should examine social support at later time 
points, as it is likely psychosocial benefits of companionship and emotional support that might be more evident to youth at later time points. In addition, we are working with a rather homogenous sample and therefore our findings cannot be generalized to more diverse samples. Many of our youth grew up in high resource and homogenous areas and that may have impacted how open youth are to receiving support and how trusting they are of adults. Further, it is possible that youth in more diverse and lower resource areas experience more adversity and barriers that would require different types of social support. It is possible that our findings are applicable to more heterogeneous groups and future studies should examine that possibility. 


\section{References}

Allen, J. P., Hauser, S. T., O'Connor, T. G., \& Bell, K. L. (2002). Prediction of peer-rated adult hostility from autonomy struggles in adolescent-family interactions. Development and Psychopathology, 14, 123-137.

Beam, M., Chen, C., \& Greenberger, E. (2002). The nature of adolescents' relationships with their "very important" nonparental adults. American Journal of Community Psychology, $30(2), 305-325$.

Bokhorst, C. L., Sumter, S. R. and Westenberg, P. M. (2010), Social Support from Parents, Friends, Classmates, and Teachers in Children and Adolescents Aged 9 to 18 Years: Who Is Perceived as Most Supportive?. Social Development, 19, 417-426. doi:

10.1111/j.1467-9507.2009.00540.x

Bronfenbrenner, U., \& Morris, P. A. (2006). The bioecological model of human development. In R. M. Lerner (Ed.), Handbook of child psychology: Vol. 1. Theoretical models of human development (6th ed.). Hoboken, NJ: Wiley. Editors-in-chief: W. Damon \& R. M. Lerner.

Brown, B. (2004). Adolescents' relationships with peers. In R. Lerner \& L. Steinberg (Eds.), Handbook of adolescent psychology (2nd ed., pp. 363-394). New York: Wiley.

Buhrmester D, \& Furman, W. (1987). The development of companionship and intimacy. Child Development, 58, 1101-1113.

Chang, E. S., Greenberger, E., Chen, C., Heckhausen, J. and Farruggia, S. P. (2010), Nonparental Adults as Social Resources in the Transition to Adulthood. Journal of Research on Adolescence, 20, 1065-1082. doi: 10.1111/j.1532-7795.2010.00662.x 
Chu, P. S., Saucier, D.A. \& Hafner, E. (2010). Meta-analysis of the relationships between social support and well-being in children and adolescents. Journal of Social and Clinical Psychology, 29(6), 624-645.

Cicognani, E. (2011). Coping Strategies With Minor Stressors in Adolescence: Relationships With Social Support, Self-Efficacy, and Psychological Well-Being. Journal of Applied Social Psychology, 41(3), 559-578. doi: 10.1111/j.1559-1816.2011.00726.x/full

Cobb, S. (1976). Presidential address: Social support as a moderator of life stress. Psychosomatic Medicine, 38(5), 300-314.

Cohen, S. \& Wills T A. (1985). Stress, social support, and the buffering hypothesis. Psychological Bulletin, 98:310-57.

Cutrona, C. E. (2000). Social support principles for strengthening families in Canavan, J., Dolan, P., and Pinkerton, J. (eds) Family support in disadvantaged families. pp103-122. Dublin: Routledge.

Dedoose Version 6.1.18, web application for managing, analyzing, and presenting qualitative and mixed method research data (2015). Los Angeles, CA: SocioCultural Research Consultants, LLC (www.dedoose.com)

Demaray, M. K., \& Malecki, C. K. (2002). Critical levels of perceived social support associated with student adjustment. School Psychology Quarterly, 17, 213-241.

Dolan, P., \& McGrath, B. (2006) Enhancing support for young people in need: Reflections on informal and formal sources of helping. In P. Dolan, J. Pinkerton, \& J. Canavan (Eds.), Family support as reflective practice (pp. 149164). London: Jessica Kingsley Publications. 
DuBois, D. L., \& Silverthorn, N. (2005). Characteristics of natural mentoring relationships and adolescent adjustment: Evidence from a national study. Journal of Primary Prevention, 26, 69-92.

Furman, W. \& Buhrmester, D. (1992). Age and sex differences in perceptions of networks of personal relationships. Child Development, 63, 103-115

Furman, W., \& Buhrmester, D. (1985). “Children's perceptions of the personal relationships in their social networks." Developmental Psychology, 21(6), 1016-24. doi:10.1037/00121649.21.6.1016.

Greenberger, E., Chen, C. \& Beam, M. (1998). The role of "very important" nonparental adults in adolescent development. Journal of Youth and Adolescence, 27(3), 321-343.

Haddad, E., Chen, C., \& Greenberger, E. (2011). The role of important non-parental adults (VIPs) in the lives of older adolescents: A comparison of three ethnic groups. Journal of Youth and Adolescence, 40, 310-319. doi:10.1007/s10964-010- 9543-4.

Harris, J. R. (1998). The Nurture Assumption. New York: Free Press

Hirsch, B. J., Deutsch, N. L., \& DuBois, D. L. (2011). After-school centers and youth development: Case studies of success and failure. New York: Cambridge University Press.

Hirsch, B. J., Roffman, J. G., Deutsch, N. L., Flynn, C. A., Loder, T. L., \& Pagano, M. E. (2000). Inner-city youth development organizations: Strengthening programs for adolescent girls. Journal of Early Adolescence, 20(2), 210-230. doi: 10.1177/0272431600020002005

Kalil, A., \& Ziol-Guest, K. M. (2008). Teacher support, school goal structures, and teenage mothers' school engagement. Youth \& Society 39, 524-548. 
Kaynak, O., Lepore, S.J., \& Kliewer, W. (2011) Social moderation of the relation between community violence exposure and depressive symptoms in an urban adolescent sample. Journal of Social and Clinical Psychology, 30, 250-269.

Lerner, R. M. (2002). Concepts and theories of human development (3rd ed.). Mahwah, NJ: Lawrence Erlbaum.

Malecki, C. K., \& Demaray, M. K. (2003). What types of support do they need? Investigating student adjustment as related to emotional, informational, appraisal, and instrumental support. School Psychology Quarterly, 18(3), 231-252.

Rhodes, J. E. (2002). Stand by me: The risks and rewards of mentoring today's youth. Cambridge, Mass.: Harvard University Press.

Richman, J. M., Rosenfeld, L. B., \& Bowen, G. L. (1998). Social support for adolescents at risk of school failure. Social Work, 43, 309-323.

Smentana, J. G., Campione-Barr, N., \& Metzger, A. (2006). Adolescent development in interpersonal and societal context. Annual Review of Psychology, 57, 255-284

Somers, C.L., \& Owens, D., Piliawsky, M. (2008) Individual and social factors related to urban African American adolescents' school performance. The High School Journal, 91,1-11.

Tracy, E. M., \& Biegel, D. E. (1994). Preparing social workers for social network interventions in mental health practice. Journal of Teaching in Social Work, 10(1/2), 19-41.

Wills, T. A., \& Shinar, O. (2000). Measuring perceived and received social support. In S. Cohen, L. G. Underwood, \& B. H. Gottlieb (Eds.), Social support measurement and intervention: A guide for health and social scientists (pp. 86-135). Oxford: Oxford University Press. 
W.T. Grant Foundation (2011). Current Research Interests. Obtained from: http://www.wtgrantfoundation.org/funding_opportunities/current_research_interests.

Yin, R.K. 2010. Qualitative Research from Start to Finish. Guilford Press.

Zeldin, S., Larson, R., Camino, L., \& O’Connor, C. (2005). Intergenerational relationships and partnerships in community programs: Purpose, practice, and directions for research. Journal of Community Psychology, 33(1), 1-10. doi:10.1002/jcop.20042 
Appendix A

Table 1. Social Support Excerpts

\begin{tabular}{|l|l|l|}
\hline Type & Coding Definition & Example \\
\hline $\begin{array}{l}\text { Emotional } \\
\text { Support }\end{array}$ & $\begin{array}{l}\text { Allow discussion of feelings, } \\
\text { expression of concerns/worries; } \\
\text { indicate sympathy, approval, } \\
\text { caring, acceptance of person }\end{array}$ & $\begin{array}{l}\text { “..there's not really a boundary that I } \\
\text { feel like I need to stop with her. I can } \\
\text { just be totally open and tell her } \\
\text { anything." }\end{array}$ \\
\hline $\begin{array}{l}\text { Instrumental } \\
\text { support }\end{array}$ & $\begin{array}{l}\text { Provide money, household goods, } \\
\text { tools, transportation, child care, } \\
\text { assistance with cooking, cleaning, } \\
\text { shopping, repairs }\end{array}$ & $\begin{array}{l}\text { "[VIP] took me in while my parents } \\
\text { "[Vnt away and stuff like that." } \\
\text { paper one time because she was an } \\
\text { English major" }\end{array}$ \\
\hline $\begin{array}{l}\text { Informational } \\
\text { support }\end{array}$ & $\begin{array}{l}\text { Provide information about } \\
\text { resources, suggest alternative } \\
\text { courses or action, provide advice } \\
\text { about effectiveness }\end{array}$ & $\begin{array}{l}\text { "[VIP] gave advice mainly about high } \\
\text { school and the transition from there and } \\
\text { just kind of like daily stuff- 'this is a } \\
\text { good tip to do." }\end{array}$ \\
\hline $\begin{array}{l}\text { Companionship } \\
\text { support }\end{array}$ & $\begin{array}{l}\text { Provide partner for sports, outdoor } \\
\text { activities, movies, theater, } \\
\text { museums, restaurants, shopping, } \\
\text { parties, trips }\end{array}$ & $\begin{array}{l}\text { "[being with VIP] makes me feel like I } \\
\text { have like someone that I can turn to } \\
\text { when I need him. And like a good } \\
\text { friend that I can just go and do fun stuff } \\
\text { with." }\end{array}$ \\
\hline Validation & $\begin{array}{l}\text { Provide consensus information re } \\
\text { prevalence of problems, } \\
\text { normativeness of individual's } \\
\text { behavior/feelings, individual's } \\
\text { relative status in population. }\end{array}$ & $\begin{array}{l}\text { 'that's one of the higher scores in all } \\
\text { the sections. Good job.' One time I got } \\
\text { the highest score and [VIP] told me } \\
\text { that and I felt really good about it." }\end{array}$ \\
\hline
\end{tabular}

Table 2. Percentages of Social Support Across VIPs

\begin{tabular}{|l|c|c|c|c|c|}
\hline VIP Role & Companionship & Emotional & Instrumental & Informational & Validation \\
\hline Kin & $33.7 \%$ & $27.6 \%$ & $20.1 \%$ & $30.8 \%$ & $35 \%$ \\
\hline Non-Kin & $31.6 \%$ & $\mathbf{3 7 . 7 \%}$ & $30.9 \%$ & $\mathbf{4 0 . 5 \%}$ & $28.9 \%$ \\
\hline Teachers & $\mathbf{3 4 . 7 \%}$ & $21.5 \%$ & $\mathbf{3 3 . 9 \%}$ & $28.6 \% \%$ & $\mathbf{3 6 . 1 \%}$ \\
\hline Total & $100 \%$ & $100 \%$ & $100 \%$ & $100 \%$ & $100 \%$ \\
\hline
\end{tabular}


Conceptualizing Social Capital Within a Positive Youth Development

Framework: The Case of Youth Adult Relationships

Shannon M. Varga

University of Virginia 


\begin{abstract}
In the field of developmental psychology, social capital has been seen as an important resource that adults provide youth because of its links to youth's academic achievement, behavioral wellbeing, and psychological well-being. Despite knowing how important this construct is, researchers have struggled with conceptual clarity and uniformity in measurement. This paper compiles traditional definitions of social capital, discusses how it has been measured in studies of youth-adult relationships, and points out limitations. I then theoretically connect social capital with a positive youth development (PYD) framework in order to allow for more conceptual clarity and appropriate measurement and discuss research that has moved in that direction. Ultimately, I put forth a definition of social capital that synthesizes the major components of both social capital and PYD theories. I argue that for social capital to be useful for the field of youth development, its definition and measurement must include a youth's economic, social, and psychological resources as well as an understanding of how those resources are accessed and exchanged through bidirectional interactions between youth and adults and institutions.
\end{abstract}




\section{Introduction}

Social capital, colloquially recognized as social resources that help people get ahead in life, is considered theoretically important for youth's development (Furstenberg \& Hughes, 1995). In fact, Ferguson (2006) posited that social capital was the second most influential factor, behind poverty, on children's development and future success. She went on to suggest that social capital is beneficial when used as a lens to examine outcomes related to youth's wellbeing (Ferguson, 2006). While social capital has been widely used in the fields of sociology and economics, the field of psychology still approaches the use of social capital as an explanatory construct with much skepticism because of the lack of precision in definition and measurement (Enfield \& Nathaniel, 2013).

Within the field of developmental psychology, adults have been considered an important source of social capital for children and youth (Chang et al., 2010). However, researchers have struggled to empirically translate the structural level concept of social capital to the individual and psychological domain when examining youth-adult relationships. There has been much empirical mistreatment of social capital, with the majority of researchers omitting several components of the original definitions from measurement. In this paper, I will present traditional definitions of social capital and discuss how it has been measured in studies of youth-adult relationships. I will then argue that combining social capital with a positive youth development (PYD) framework would allow for more conceptual clarity and appropriate measurement and discuss research that has moved in that direction. In doing so, I put forth a definition of social capital which synthesizes the major components of both social capital and PYD theories. I argue that for social capital to be useful for the field of youth development, its definition and measurement must include a youth's economic, social, and psychological resources as well as an 
understanding of how those resources are accessed and exchanged through bidirectional interactions between youth and adults and institutions.

\section{Social Capital}

Although many definitions of social capital exist, three major theories have guided the literature. Pierre Bourdieu (1985), a sociologist with interests in social hierarchy, first defined social capital as the "the aggregate of the actual or potential resources which are linked to possession of a durable network of more or less institutionalized relationships of mutual acquaintance or recognition" (p. 248). Bourdieu specifically differentiates the presence of resources and the relationships that allow access to them. This differentiation speaks to an intentionality required on the behalf of the individual to generate social capital, in that the presence of resources is not enough, a person needs to be able to access and engage with the resources to benefit from them (Portes, 1998). Bourdieu theorized that social capital is most beneficial to the wealthy because he assumed that those with greater economic resources have more connections to socially valued resources whereas those with fewer economic resources have fewer connections to socially valued resources, which allows wealthy individuals to maintain their social class and privileges (Bourdieu, 1985).

Rather than examining individual-level social capital benefits, James Coleman (1988) considered social capital as a social good. His work with high school students led him to conclude that students' and schools' success were a result of the complex social structures which bonded the students, school, and community (Coleman, 1987). He felt that norms, interpersonal trust, and networks of social contexts shape individuals' actions; that is, social capital is embedded within dense social structures, which shape the actions of individuals within the structure (Coleman, 1988). Within his definition, trustworthiness of the social environment and 
reciprocity are seen as important to social capital. He also acknowledges that individuals do benefit from social capital, however, he envisioned social capital as a construct that is more applicable to the "public good" (Enfield, 2008).

Robert Putnam (2000), a political scientist interested in civic engagement, conceptualized social capital at the community level. In his book (2000), he defined social capital as referring to "connections among individuals- social networks and the norms of reciprocity and trustworthiness that arise from them" (p. 19). He posed his theory after viewing, what he felt was, a decline in community engagement and connection in the United States. He believed that the more engaged citizens of a country were, the more the overall community (read nation) and individuals would benefit. Most similar to Coleman's theory, Putnam emphasized the group level implication of social capital.

To summarize, the three major theorists of social capital treated social capital as accumulating benefits at different levels. Bourdieu felt social capital was driven at the individual level for the purposes of maintaining individuals' placement within the social hierarchy. Coleman felt inequalities between groups (in education, wealth, etc.) were maintained because of social capital. Putnam felt social capital was more relevant to a societal level of civic engagement within a nation (see table 1 for summary). While all three of these theorists felt social capital was most present at different levels of society and for different reasons, there are similar components referenced in each: connections of individuals to networks, resources, trust, and reciprocity (Enfield, 2008). In addition, all three theorists presented definitions of social capital in which the person (or group) who has social capital benefits, while the person who does not stagnates. Putnam went one step further in describing two different forms of social capital. 


\section{Forms of Social Capital}

Putnam (2000) discussed two different forms of social capital, bonding and bridging. Bonding, or exclusive, social capital is the value (e.g. psychological resource) that is produced from connections between people who already know one another or share a common identity (e.g. family, culture). Examples of groups or organizations that are likely to produce bonding social capital are: theological groups, country clubs, and gender specific organizations. The value that is produced from interactions with similar individuals can be considered akin to social and psychological support. Because of this, bonding social capital has been referred to as useful for "getting by" (Putnam, 2000). However, it has also been asserted that this type of social capital "maintains homogeneity and tends to reinforce exclusive identities" (Enfield, 2008, p. 7). While bonding social capital networks can be important for psychological support and engendering reciprocity, it is also likely the mechanism that Bourdieu was concerned with when discussing social class reproduction. That is, bonding social capital in an extreme form might lead to exclusion of groups that are different from one another (e.g. the KKK; Putnam, 2000) and could lead to reproduction of current social conditions.

Bridging, or inclusive, social capital expands beyond the shared sense of identity of bonding social capital to include people from different groups. Bridging social capital networks provide links (i.e. social connections) to external resources (i.e. economic or social resources) and are useful for spreading information across religious, class, and ethnic lines (Putnam, 2000). This form of social capital is likely what comes to mind for most people when thinking about social capital and can be considered useful for "getting ahead" (e.g. professional advancement; Putnam, 2000). While bonding social capital theoretically operates similarly across social 
classes, it could be argued that bridging social capital is more important for those with lower amounts of economic and social resources (Putnam, 2000).

Though bonding capital is seen as more important for well-being and bridging capital is seen as more important for information and advancement, both have been theoretically described as horizontal forms of social capital. They are both considered horizontal because the connections made in both forms are thought to be between individuals in similar economic and social status, though this range of people is wider for bridging social capital (Enfield, 2008). Different from both of these is linking social capital, which is considered a vertical form of social capital.

Proposed by Woolcock (1998), linking social capital is seen when connections made are between people from completely different economic classes (or several rungs apart on the economic ladder). In addition, it is thought that the people to whom one is being connected are from outside the connecter's community, so that people can gain access to resources that are not within their community. Linking social capital can be seen as a more extreme version of bridging capital (Enfield, 2008). While it seems that linking social capital networks are often built upon bridging social capital networks, linking social capital more often has to do with larger factors such as expansion of power, political influence, or financial resources. Due to conceptual overlap between bridging and linking capital, within this paper I combine the two forms into a single category, which I call bridging capital. Therefore, under this combined category, bridging capital can now occur vertically and horizontally because it will ultimately address social capital that promotes "getting ahead."

These forms (see table 2 for summary), while presented by Putnam, are implicitly present in Bourdieu and Coleman's definitions as well. Bonding social capital is useful for engendering 
reciprocity and trust amongst individuals, which Bourdieu and Coleman felt were essential to the definition of social capital. In addition, as previously mentioned, bonding social capital can breed exclusion of different groups and so can be seen as a mechanism for reproducing social class or maintaining gaps between groups. Bridging social capital refers more to the resource and mobility function of social capital- it is the information and mobility that allow the well connected to be successful. However, these complex definitions have not often translated into empirical examinations of social capital.

[Insert table 2 here]

\section{Empirical Examinations of Social Capital and Youth Adult Relationships}

From the aforementioned definitions of social capital, many developmental researchers have examined social capital as a resource that adults can offer youth. Previous studies have most often focused on the bridging social capital networks, viewing adults as disseminators of information and connectors to professional advancement for youth. Put another way, previous studies view social capital as encapsulating economic and social resources. For example, Chang and colleagues (2010) found that low-income youth's perceptions of their very important, nonparental adults' (VIP's) social capital were positively related to youth's grades and educational expectations one year later. Social capital was conceptualized as the VIP's level of educational attainment and engagement in misconduct, where higher levels of educational attainment and fewer instances of engagement in misconduct indicated higher levels of social capital. Among research that treats social capital as social or economic resources, Chang and colleagues' (2010) findings are common; that is, VIPs with greater levels of economic social capital are associated with better academic outcomes for youth (Gaddis, 2012; Erickson, McDonald, \& Elder, 2009; Chen et al., 2003; Dreher \& Cox, 1996). 
Exposing youth to adults with higher levels of educational attainment/income seems like a simplistic and desirable way to transfer social capital. However, this is missing several key components of social capital that theorists have indicated are important. Namely, the bonding social capital portion, which addresses trust, connection, and reciprocity, is absent from this assessment of social capital. The line of research that treats social capital as economic resources, which often reduces social capital to a single component, operates under the assumption that adults with elevated levels of educational attainment/income have networks of people with similar levels of educational attainment/income, and that these connections are useful to youth who might not have anyone in their networks with that level of educational attainment (Gaddis, 2012). However, researchers working from this frame do not confirm that the process of transference is occurring. In other words, they measure the status of the adult but do not typically measure the youth's perceptions of levels of connectedness, trust, or reciprocity in their relationships with those adults, factors that may be important for determining whether youth actually benefit from that social capital. Thus, such studies typically provide assessments of the presence of potential social capital but not the actual access of that capital by youth. Many of these limitations are a function of taking a concept from sociological literature that treats social capital as inherently attached to institutions and economics, whereas examining youth-adult relationships requires researchers to take individual interactions into account. The theoretical definitions of social capital as they are do not lend themselves to exploring individual interactions and as a result the above line of literature has focused more on social capital as a economic resource and has not taken into account the interactions that underlie social capital. Another less explored line of research has focused more on bonding social capital networks, wherein adults provide youth with psychological support, which is theoretically seen 
as important to youth's success (Wentzel, 1998). Brewster and Bowen (2004), for example, examined the association between teacher supports and school engagement of Latino middle and high school students. The authors consider teacher support as the degree to which teachers listen to, encourage, and respect their students. The authors found significant associations between youth's perceptions of teacher support and school engagement; as perceptions of teacher support increased, levels of problem behaviors decreased and levels of school meaningfulness increased. The authors assert that these findings point to the importance of adult social capital for youth. In regards to teacher social capital, they felt the support offered by teachers affects school engagement and thus educational attainment (Brewster \& Bowen, 2004). This finding is consistent with much of the literature on teacher social capital and academic outcomes for youth (Herman \& Tucker, 2000; Wentzel, 1998). This study falls into the trap of the assumption that presence of resources equates to access of resources, as discussed above. Bourdieu (1985) differentiated presence versus access of resources to emphasize the point that simply because resources are available to a person, does not mean that they have access to them; in this case, we do not know if the youth utilized their teacher supports and so cannot definitively attribute their positive behaviors and attitudes to teacher support. Further, the authors seem to conflate teacher emotional support with social capital, which disregards the economic and social portions of the definition. Though this study does provide insight that emotional support might be an important part of social capital, it does not fully assess social capital as a multidimensional construct.

In sum, the literature on social capital and youth-adult relationships often omits aspects of the original definition, for example by focusing on bonding or bridging social capital. Despite the original definitions of social capital positing that there are multiple necessary components, this has not translated well into developmental research. Further, social capital theories are more 
focused on the resources produced from relationships and how those resources benefit or oppress groups of people rather than understanding the actual relationships and underlying interactions that are necessary to produce social capital. The result is that much of the previous research on social capital in youth-adult relationships has treated social capital as resources and has often not furthered our understanding of how social capital is developed and produced in these relationships. Yet I believe that linking the Positive Youth Development (PYD) framework, an increasingly common frame for developmental research that emphasizes both individual and structural level factors (Lerner, Lerner, Almerigi, \& Theokas, 2005), with social capital could add to how we view social capital and assist with appropriate measurement. I will now define PYD and discuss social capital's relevance to the PYD perspective and models.

\section{Positive Youth Development}

The PYD perspective emerged in the 1960 s as an alternative to traditional medical models of human development. Traditional medical models often describe development from a fixed, deficit, and individualized standpoint that results in reactive interventions to existing maladaptive behaviors (Lerner, Lerner, Almerigi, \& Theokas, 2005). In contrast, the PYD approach emphasizes the plasticity of human development, the promotion of adaptive behaviors and positive outcomes, and alignment between youth and the contexts they are in (Lerner, et al., 2005). The fixed view of human development perpetuates a narrative of genetic determinism for youth (Damon, 2004), whereas PYD models posit the dynamic nature of development as providing countless opportunities to promote positive behaviors and youth as active agents of their own development. Shifting away from deficit models, PYD views all youth as having the potential for positive development and this creates a healthier narrative of youth behavior and their capacity for successful development (Lerner, Dowling, \& Anderson, 2003). Drawing from 
developmental systems and ecological theories, the PYD perspective views youth as having bidirectional interactions with the various contexts they are in and hypothesizes that when these interactions are mutually beneficial, they can promote adaptive behaviors (Bronfenbrenner, 2005; Lerner, 2002). Overall, the theory of PYD complicates the traditional narrative of youth development by offering a strengths-based perspective of how youths' interactions with people and institutions can promote positive developmental change in the youth and contributions to their ecologies (Lerner, Dowling, \& Anderson; 2003). The PYD approach also focuses on fostering conditions in external contexts (e.g. institutions) that lead to thriving in youth from various external contexts (Lerner, von Eye, Lerner, Lewin-Bizan, \& Bowers, 2010). This overall perspective has been successfully translated into a number of specific conceptual models. In this paper, I use Lerner's (2004) Five C's model of PYD because of its prevalence in the empirical, developmental literature.

\section{The Five C's of PYD}

Rich Lerner's (2004) Five C's Model of PYD has been empirically validated and is widely utilized in studies of PYD. There were two key hypotheses that accompanied the formulation of this model. The first is that five characteristics or indicators of optimal development could conceptualize the major tenants of the PYD theory: competence, confidence, connection, character, and caring/compassion. Competence refers to the youth's positive perception of his or her actions in domain specific areas, such as academic, social, cognitive, and vocational. Confidence refers to the youth's overall, internal, sense of self-worth and selfefficacy. Connection refers to the creation of positive relationships with people and institutions through bidirectional exchanges with peers, family, school, or communities. Character refers to respect for societal and cultural norms, a sense of right and wrong, integrity, and possession of 
standards for correct behaviors. Caring/compassion refers to a sense of sympathy and empathy for other people. A youth is considered to be thriving if he or she has these five characteristics (Lerner, 2005). Furthermore, Lerner later proposed a Sixth C, contribution. According to the model, when a youth develops the Five C's over time (i.e. he or she is thriving), he or she will be on a pathway towards an idealized adulthood (Lerner, 2005); that is, the thriving youth will go on to have an adult life distinguished by mutually reinforcing contributions to his or her self and his or her various ecologies (e.g. family, community, and institutions).

The hypotheses set forth by the 5 C's model have been extensively supported through research using data from the national longitudinal 4-H study of PYD. The 4-H study was designed to test the idea that when youth's strengths are aligned across their ecologies (e.g. family, school, and community resources) PYD will occur as evidenced by the presence of the Six C's (Lerner, et al., 2009). The study began in 2002 when youth were in fifth grade and has over 6000 participants through grade 12 (Lerner, et al., 2010). Lerner and colleagues (2005) used data from the first wave of data and found evidence of Five C's being represented as latent constructs converging on a second-order construct, PYD. Phelps and colleagues (2009) extended these findings for the next two waves of data (Grades 6 and 7) and found that PYD continues to be a robust construct through the later grades of early adolescence. Furthermore, other researchers have found evidence that PYD is positively related to contribution and negatively associated to risk and problem behaviors at a later grade (Jelicic et al., 2007).

The second hypothesis of the Five C's perspective, which is highly aligned with the PYD perspective, is that youth are likely to thrive when their strengths are aligned with the various ecological assets available to them (Lerner et al., 2004; Benson et al., 2006). Many studies have established a positive link between youth strengths- operationalized as intentional self-regulation 
skills in Selection, Optimization, and Compensation (SOC; Freund \& Baltes, 2002) ${ }^{1}$ - and PYD

and youth contribution, as well as a negative link to problem behaviors (Gestsdottir \& Lerner, 2007). Taken together, the Six C's map directly onto many aspects of the PYD perspective while highlighting the importance of youth-context alignment in developing the characteristics.

\section{Social Capital and Positive Youth Development}

The connections between PYD and social capital in terms of their inclusion of connections to networks, resources, and reciprocity as key concepts are clear. However, upon further examination, it is evident that the definition of social capital can benefit greatly from inclusion of a PYD perspective. PYD and the Five C's model both place a heavy emphasis on bidirectional interactions. While Bourdieu, Coleman, and Putnam discuss reciprocity, they only implied that both parties benefit from the interaction, whereas PYD's emphasis on bidirectional interactions asserts both youth and adults are active participants in interactions. This brings forward the idea of youth agency within social capital, that youth are not simply passive receivers of social capital but active seekers of resources. Despite the use of reciprocity in traditional definitions, previous studies often include unidirectional examinations of social capital; that is, only one perspective is measured (either the youth or the adult) in most studies. Inclusion and emphasis of bidirectional interactions in the definition of social capital would require explicit assessments of interactions in youth adult relationships. In addition, understanding that youth actively interact with their contexts and potentially seek out social capital would call for an inclusion of in-depth youth perspectives in studies of social capital, a feature which is often missing.

\footnotetext{
${ }^{1}$ Selection refers to choice of goals, immediate and long term. Optimization refers to the ability to identify and pursue resources necessary to achieve goals. Compensation refers to the understanding that not all goals are achievable and the ability to move beyond the failures or find alternative goals.
} 
Social capital aligns with the Five C's Model's emphasis on youth-context alignment. More specifically, the Five C's model supports the idea of developmental assets existing across youth's ecologies (e.g. family, community) and argues that youth gain resources from these assets. Under Bourdieu's (1985) definition, social capital can be conceptualized as the resource that emerges from the youth's relationships and interactions with various adults and institutions (e.g. programs) in their ecologies. Through these interactions, youth develop their own social capital, which assists in their development and which ultimately they can call upon to contribute back into their ecologies.

Finally, social capital can benefit from the PYD perspective by taking an ecological approach to understanding development. The Five C's Model highlights both Connection to external resources and internal Competence as being necessary for thriving. While previous studies of social capital have largely disregarded either bonding or bridging social capital by examining them separately. Given that bridging social capital is related to connecting youth to external economic and social resources and bonding social capital is related to boosting internal competencies through psychological supports, viewing it within a PYD frame emphasizes the importance of including both bonding and bridging social capital. Ultimately, combining social capital with a PYD frame places emphasis on bidirectional interactions between individuals and institutions. In studying youth-adult relationships this calls for examining interactions between youth and adults in order to understand how social capital is produced and transferred.

\section{Empirical Examples of Social Capital and PYD}

There have been a few examples of studies that have implicitly included PYD tenants when examining social capital, though they do not explicitly utilize the PYD frame or language. Jarret, Sullivan, and Watkins (2005) conducted in-depth qualitative interviews with high-school 
aged students $(n=34)$ in order to understand the youth's experiences with social capital formation in positive youth-adult relationship. The youth were involved in programs that aimed to help youth reach goals and connect them to their communities. Operating under a combination of Bourdieu's (1985) and Coleman's (1988) definitions of social capital they created an interview protocol that aimed at understanding the youth's perceptions of the resources available to them and their engagement with those resources by asking about interactions with adults in the community. The authors found that youth felt their relationships with adults provided them with myriad resources: information, assistance, exposure, and support and engagement. The information topics ranged from day-to-day life skills, such as the correct usage of certain tools, to major life skills topics, such as how to make an informed decision about which college to attend. In terms of assistance, the youth provided examples of times when adults in the program directly helped them achieve a goal, such as helping youth win an election. In addition, the adults in the program often took youth to visit workplaces where the youth had future aspirations to work. The youth felt these visits offered them concrete understandings of previously obscure worlds of adulthood as well as networks for future internship and job opportunities. And finally, the youth felt the adults demonstrated their support of the youth by offering verbal and enthusiastic encouragement of their work; in turn, the youth felt the support motivated them to work harder. In all of the aforementioned cases, the youth felt their relationships with these adults were what gave them access to key resources and unique experiences that aided them in being more successful in their lives.

Jarret, Sullivan, and Watkins' (2005) study provided important insights into what bonding and bridging social capital (i.e. psychological and social resources) look like in youthadult relationships and confirming that youth find both forms of social capital important. In 
addition, this study provided the youth's perspective of how they were active in their relationships with adults and what they found important- a perspective that is often missing. Furthermore, the study examined the interactions that led to transference of social capital. However, this study was limited in that the youth were engaged in programs that were specifically designed to engender social capital, which is an idealized experience, as the majority of youth are not enrolled in programs specifically aimed at generating social capital.

In another study, Philips' (2008) examined disadvantaged youth's perceptions of social capital in their mentoring relationships. The author conducted interviews with 18 youth and 32 adults including parents, mentors, and other adults in the youth's lives. The author provided two case studies of youth of low socioeconomic status who were described as "socially excluded" (Philips, 2008, p 23). These youth had been kicked out of school, and were referred to mentors who volunteered to work with at-risk youth. In both cases, the youth reported feeling validated by their mentor's treatment of them as normal youth and not problem youth. They both felt that the mentor's belief and valuing of them increased their self-esteem. The parents of both of the youth also confirmed that they felt their children had become more confident and felt that this attribute increased the youth's engagement in education. In both cases, the youth chose to go back to school. In one case, the youth reported his mentor acted as an advocate on his behalf and that advocacy was crucial to his being accepted back into school. This study's most important contribution to the social capital literature is that it provides concrete pathways through which adults are helping youth to generate their own social capital from the youth's perspective. While much of the literature finds correlations between adult support and positive youth outcomes, this study is unique in that the youth confirmed that psychological and social resources the adults provided them with were perceived as important to their trajectories. These findings, like Jarret 
and colleagues' (2005) findings, also offer evidence that adults can offer youth both bonding and bridging capital. In addition, Philips (2008) had the strength of parent interviews as an added confirmatory perspective to what the youth were reporting.

While neither of the two aforementioned studies explicitly utilized a PYD framework, they looked at resources in positive youth-adult relationships from the youth perspective, which is very reflective of the PYD framework. In addition, they focused on the processes of developing and transferring social capital. Both studies focused on interactions in relationships and were able to provide clear links between interactions with adults and impacts on youth's outcomes, from the youth's perspectives.

\section{Conclusion}

Despite the many facets of social capital theories, social capital has often either been reduced to single constructs, or measured in a way that still omitted several of its constructs, in developmental literature (Gaddis, 2012). Previous studies have also often examined aspects of bonding or bridging capital, though both are a part of social capital as a whole. Further, social capital theories emphasize what is being exchanged in society rather than how it is being exchanged. I propose that linking social capital to PYD literature could expand the definition of social capital further in a way that might engender more precision in measuring social capital. For the purposes of examining youth adult relationships, I propose the following definition of social capital which combines social capital with PYD components: social capital is a combination of economic, social, and psychological resources, which can be accessed and exchanged through bidirectional interactions between youth and adults and institutions. From social capital, we maintain the presence of bonding social capital (i.e. psychological resource) and bridging social capital (i.e. economic and social resources). From PYD we gain an emphasis 
on bidirectional interactions and youth agency. Further, we gain the understanding that both bonding and bridging social capital are necessary for a youth to have social capital. Social capital is not economic resources, networks, or psychological support- it is all of those things combined.

This combination of social capital and PYD has implications for measuring and examining social capital in youth adult relationships. First, it requires the addition of youth voice, which is often missing from many studies of social capital. The new definition also requires researchers to be mindful of the interactions or process through which social capital is transferred. Further, it would require studies to examine bonding and bridging social capital in a single study, as they are two halves of the whole. All of these suggestions would lead to greater understanding of how adults can help youth develop greater amounts of social capital.

By using social capital as an explanatory construct we gain an ecological assessment of the resources youth have. Bridging social capital is necessary in order for youth to get ahead by connecting them to external resources and networks, bonding social capital is necessary for youth to get by, by promoting their internal competencies (Putnam, 2000)- both need to be present to truly represent social capital, and for youth ${ }^{2}$ to thrive. By assessing both we have a way of quantifying the levels of social capital in youth's lives and a clearer point of intervention. Given how important previous studies have found social capital is in youth's development (Ferguson, 2006) it is important that we are able to empirically examine it so that we may better understand how to engender it in youth who have less social capital.

\footnotetext{
${ }^{2}$ As previously discussed, bridging social capital might be more useful to youth with lower levels of social and economic resources, and so may operate differently or not at all for youth with high levels of social and economic resources. This should be further explored.
} 


\section{References}

Benson, P. L., Scales, P. C., Hamilton, S. F., \& Semsa, A., Jr. (2006). Positive youth development: Theory, research, and applications. In R. M. Lerner (Ed.). Theoretical models of human development. Volume 1 of Handbook of Child Psychology (6th ed.). Hoboken, NJ: Wiley.

Bourdieu P. (1985). The forms of capital. In J. G. Richardson (Ed.), Handbook of Theory and Research for the Sociology of Education, (p. 241-58). New York: Greenwood.

Brewster, A. B., \& Bowen, G. L. (2004). Teacher support and the school engagement of latino middle and high school students at risk of school failure. Child and Adolescent Social Work Journal, 21(1), 47-67.

Bronfenbrenner, U., \& Morris, P. A. (2006). The bioecological model of human development. In R. M. Lerner (Ed.), Handbook of child psychology: Vol. 1. Theoretical models of human development (6th ed.). Hoboken, NJ: Wiley. Editors-in-chief: W. Damon \& R. M. Lerner.

Chang, E. S., Greenberger, E., Chen, C., Heckhausen, J., \& Farruggia, S. P. (2010). Nonparental adults as social resources in the transition to adulthood. Journal of Research on Adolescence, 20(4), 1065-1082.

Chen, C., Greenberger, E., Farruggia, S., Bush, K., \& Dong, Q. (2003). Beyond parents and peers: The role of important non-parental adults (VIPs) in adolescent development in China and the United States. Psychology in the Schools, 40, 35-50.

Coleman, J. S. (1988). Social capital in the creation of human capital. American Journal of Sociology, 94, 95-120.

Damon, W. (2004). What is positive youth development? Annals of the American Academy of 
Political and Social Science, 591, 12-24.

Dreher, G. F., \& Cox, T. H. (1996). Race, gender, and opportunity: A study of compensation attainment and the establishment of mentoring relationships. Journal of Applied Psychology, 81(3), 297-308.

Enfield, R. \& Nathaniel, K. C. (2013). Social capital: Its constructs and survey development. In G. G. Noam, M. Calvert, M. Emery, \& S. Kinsey (Eds.), New directions for youth development: Youth programs as builders of social capital (p. 15-30). Danvers, MA: Wiley Periodicals.

Enfield, R. (2008). Social capital and implications for positive youth development. Retrieved from http://4h.ucanr.edu/files/1225.pdf

Erickson, L. D., McDonald, S., \& Elder, G. H. (2009). Informal mentors and education: Complementary or compensatory resources? Sociology of Education, 82(4), 344-67.

Freund, A. M., \& Baltes, P. B. (2002). Life-management strategies of selection, optimization, and compensation: Measurement by self-report and construct validity. Journal of Personality and Social Psychology, 82, 642-662.

Furstenberg, F. F. \& Hughes, M. E. (1995). Social capital and successful development among at risk youth. Journal of Marriage and Family, 57, 580-592.

Gaddis, S. M. (2012). What's in a Relationship? An examination of social capital, race and class in mentoring relationships. Social forces, 90(4), 1237-1269.

Gestsdottir, S., \& Lerner, R.M. (2007). Intentional self-regulation and positive youth development in early adolescence: Findings from the 4-H study of positive youth development. Developmental Psychology, 43, 508-521.

Herman, K. C., \& Tucker, C. M. (2000). Engagement in learning and academic success among 
at-risk Latino American students. Journal of Research and Development in Education, $33,129-136$.

Jarrett, R. L., Sullivan, P. J., \& Watkins, N. D. (2005). Developing social capital through participation in organized youth programs: Qualitative insights from three programs. Journal of Community Psychology, 33(1), 41-55.

Jelicic, H., Bobek, D., Phelps, E., Lerner, J. V., \& Lerner, R. M. (2007). Using positive youth development to predict contribution and risk behaviors in early adolescence: Findings from the first two waves of the 4-H Study of Positive Youth Development. International Journal of Behavioral Development, 31(3), 263-273.

Lerner, R. M. (2002). Concepts and theories of human development (3rd ed.). Mahwah, NJ: Lawrence Erlbaum.

Lerner, R. M. (2004). Liberty: Thriving and civic engagement among American youth. Thousand Oaks, CA: Sage.

Lerner, R. M., Dowling, E. M., \& Anderson, P. M. (2003). Positive youth development: Thriving as a basis of personhood and civil society. Applied Developmental Science, 7, 172-180.

Lerner, R. M. (2005). Promoting Positive Youth Development: Theoretical and Empirical Bases. White paper prepared for the Workshop on the Science of Adolescent Health and Development, National Research Council/Institute of Medicine., September. Washington, DC: National Academies of Science.

Lerner, R. M., \& Lerner, J. V., Almerigi, J., \& Theokas, C. (Eds.). (2005). Positive youth development. Journal of Early Adolescence, 25(1), 1-144.

Lerner, R. M., von Eye, A., Lerner, J. V., \& Lewin-Bizan, S. (2009). Exploring the foundations and functions of adolescent thriving within the 4-H study of positive youth development: 
A view of the issues. Journal of Applied Developmental Psychology, 30(5), 567-570.

Phelps, E., Zimmerman, S., Warren, A. A., Jelicic, H., von Eye, A., \& Lerner, R. M. (2009). The structure and developmental course of Positive Youth Development (PYD) in early adolescence: Implications for theory and practice. Journal of Applied Developmental Psychology, 30, 571-584.

Philip, K. (2008) She's my second mum: Young people building relationships in uncertain circumstances. Child Care in Practice, 14(1), 19-33.

Portes, A. (1998). Social capital: Its origins and applications in modern sociology. Annual Review of Sociology, 24,1-24.

Puntnam, R. (2000). Bowling alone: The collapse and revival of American community. New York: Simon and Schuster.

Wentzel. K. R. (1998). Social support and adjustment in middle school: The role of parents, teachers, and peers. Journal of Educational Psychology, 86, 173-182.

Woolcock, M. (1998). Social capital and economic development: Toward a theoretical synthesis and policy framework. Theory and Society, 27, 151-208. 


\section{Appendix B}

Table 1. Summary of Theories of Social Capital

\begin{tabular}{|l|c|c|c|}
\hline \multicolumn{1}{|c|}{ Theorist } & Definition & $\begin{array}{c}\text { Level of } \\
\text { Benefit }\end{array}$ & Outcome \\
\hline Bordieu (1985) & $\begin{array}{c}\text { "The aggregate of the actual or } \\
\text { potential resources which are linked to } \\
\text { possession of a durable network of } \\
\text { more or less institutionalized } \\
\text { relationships of mutual acquaintance or } \\
\text { recognition" (p. 248) }\end{array}$ & Individual & $\begin{array}{c}\text { Social capital helps } \\
\text { maintain social } \\
\text { hierarchy by } \\
\text { reproducing social } \\
\text { class through } \\
\text { individual gains }\end{array}$ \\
\hline $\begin{array}{l}\text { Coleman } \\
(1988)\end{array}$ & $\begin{array}{c}\text { Social capital is embedded within } \\
\text { dense social structures, which shape the } \\
\text { actions of individuals within the } \\
\text { structure. Also important are trust and } \\
\text { reciprocity. }\end{array}$ & $\begin{array}{c}\text { Individual } \\
\text { and group }\end{array}$ & $\begin{array}{c}\text { Social capital helps } \\
\text { maintain inequalities } \\
\text { between groups } \\
\text { through social } \\
\text { contexts of } \\
\text { institutions }\end{array}$ \\
\hline Putnam (2000) & $\begin{array}{c}\text { "Connections among individuals- } \\
\text { social networks and the norms of } \\
\text { reciprocity and trustworthiness that } \\
\text { arise from them" (p. 19). }\end{array}$ & Community & $\begin{array}{c}\text { Social capital helps } \\
\text { maintain civic } \\
\text { engagement by }\end{array}$ \\
& $\begin{array}{c}\text { Conghections } \\
\text { through connections } \\
\text { and reciprocity }\end{array}$ \\
\hline
\end{tabular}


Table 2. Forms of Social Capital

\begin{tabular}{|l|c|c|c|}
\hline Type & Definition & Direction & Theorized Uses \\
\hline $\begin{array}{l}\text { Bonding (e.g. } \\
\text { psychological }\end{array}$ & $\begin{array}{c}\text { The value that is } \\
\text { produced from } \\
\text { connections between } \\
\text { people that already know } \\
\text { one another or share a } \\
\text { common identity }\end{array}$ & Horizontal & $\begin{array}{c}\text { Psychological well- } \\
\text { being; engendering } \\
\text { reciprocity; reinforcing } \\
\text { exclusive identities }\end{array}$ \\
$\begin{array}{l}\text { Bridging (e.g. social } \\
\text { connections and } \\
\text { economic resources) }\end{array}$ & $\begin{array}{c}\text { The value that is } \\
\text { produced from } \\
\text { connections between } \\
\text { people from different } \\
\text { groups }\end{array}$ & Horizontal & $\begin{array}{c}\text { Expansion of identities; } \\
\text { fostering reciprocity; } \\
\text { disseminating } \\
\text { knowledge; personal } \\
\text { advancement }\end{array}$ \\
\hline $\begin{array}{l}\text { Linking (e.g. social } \\
\text { connections and } \\
\text { economic resources) }\end{array}$ & $\begin{array}{c}\text { The value that is } \\
\text { produced from } \\
\text { connections between } \\
\text { people of completely } \\
\text { different economic } \\
\text { classes or communities }\end{array}$ & Vertical & $\begin{array}{c}\text { Expansion of power, } \\
\text { financial resources; } \\
\text { political influence }\end{array}$ \\
\hline
\end{tabular}


Deconstructing Social Capital in Youth Adult Relationships

\author{
Shannon M. Varga \\ Mark Vincent B. Yu \\ Haley E. Johnson \\ Nancy L. Deutsch \\ University of Virginia
}

Valerie A. Futch Ehrlich

Center for Creative Leadership 


\begin{abstract}
In the field of developmental psychology, it has been asserted that non-parental adults can be an important source of social capital for children and youth. Despite the general consensus that social capital is important for youth development, researchers have struggled to empirically examine social capital because of its theoretical complexity. This paper presents an in-depth exploratory examination of social capital in significant youth-adult relationships. Data for this study comes from 48 youth interviews (two interviews per youth) and 23 nominated significant adult interviews to examine their descriptions of social capital in their relationships. Youth provided rich descriptions of both bonding and bridging social capital in their lives characterized by economic, social, and psychological resources. Ultimately, we found the different types of social capital represent potential pathways through which social support and other social processes (e.g. mutuality, trust) can interact to impact youth internally or externally. To date, no other study has conducted an in depth qualitative examination of the process of development and exchange of bonding and bridging social capital in youth-adult relationships. The results from this paper present concrete characterizations of social capital that have the potential to inform clearer definition and precision in measuring social capital in youth-adult relationships.
\end{abstract}




\section{Introduction}

The concept of social capital has been widely utilized in sociological, economic, and political research when examining social mobility and social class reproduction (Patulny \& Svendsen, 2007). In the field of developmental psychology, it has been asserted that non-parental adults can be an important source of social capital for children and youth (Chang et al., 2010). Previous studies have suggested social capital is linked to several youth outcomes such as academic achievement (Kao \& Rutherford, 2007), educational attainment (White \& Glick, 2000), extracurricular participation (Glanville, Sikkink, \& Hernandez, 2008), self-concept (Thomason \& Kuperminc, 2013) substance use (Curran, 2007), dropout rates (Croninger \& Lee, 2001), and indicators of health and well being (Rosenfeld, Richman, \& Bowen, 1998). Despite the general consensus that social capital is important for youth development, researchers have struggled to empirically examine social capital because of its theoretical complexity. Given all the benefits of social capital, it is imperative that we understand how to empirically examine it. In a previous paper (Varga, 2016) I set forth a definition of social capital for use in youth development research that encompasses the economic, social, and psychological resources available to a youth as well as the ways in which those resources are accessed and exchanged in bidirectional interactions between youth and adults. The purpose of this study is to explore social capital in significant youth-adult relationships (YARs) using this definition as a frame.

\section{Literature review}

Social capital has multiple theoretical definitions. Pierre Bourdieu (1985) first conceptualized social capital as a compilation of resources made up of connections, networks, and reciprocal respect to which individuals may or may not have access. He felt social capital was key in social class reproduction, as access to these social resources allowed for those with 
social power to retain it and made it difficult for those without social power to access it. James Coleman (1988) expanded upon Bourdieu's definition by presenting social capital as embedded in social structures that impact individuals within the structures. But according to Coleman, social capital's ultimate effects are at the group level by creating divisions between groups of people. Robert Putnam (2000) conceptualized social capital well beyond the individual level and examined social capital from a community level. In his conceptualization, reciprocity and trust emerge from connections among individuals and social networks within the community and thus characterize and impact the community as a whole. While all three theorists included connection to networks, resources, trust, and reciprocity as important in their definitions, they introduced social capital as having main effects that occur at different levels in society: individual, group, and community.

In addition, Putnam (2000) discussed bonding and bridging forms of social capital in order to differentiate two parts of the whole definition. Bonding social capital exists within groups that share a common identity and functions as psychological support to its members as well as engenders reciprocity. Bridging social capital moves beyond shared identities and occurs between people with different identities and is useful for providing links to external resources and spreading information (Putnam, 2000).

Due to its complexity, previous studies of social capital have operated under several different definitions and utilized a wide variety of measures (e.g. SES, educational attainment, emotional support; Patulny \& Svendsen, 2007). In a previous review of the theoretical foundations of social capital (Varga, 2016), the author asserted that social capital in youth's relationships with non-parental adult (herein referred to as YARs) encompasses economic, social, and psychological resources. Under this definition, bridging social capital is captured in 
economic and social resources and bonding social capital is captured in psychological resources. However, many studies do not examine all three types of resources or explicitly identify which resource is being examined. Therefore, to help frame our current study, we will discuss previous empirical studies of social capital and explicitly identify which resources were examined (see Table 1 for listing of studies reviewed along with their definitions of social capital, measurement, and types of resources and social supports implied).

[Insert table 1 here]

\section{Studies of Economic and Social Resources}

It is common for studies that focus on the economic and social resources available to youth to define social capital generally as resources that make positive outcomes more likely (see Table 1). However, when examining YARs, researchers working within this frame consider adults with higher levels of economic or social resources to have social capital that can be transmitted to youth; that is, these studies are actually examinations of bridging social capital which use measures of economic or social resources. For example, in one study of youth's relationships with very important non-parental adults (VIPs), Chang and colleagues (2010) used the VIP's level of educational attainment and engagement in misconduct as indicators of social capital, where higher educational attainment and fewer instances of engagement in misconduct indicated higher levels of social capital. They found that low-income youth's perceptions of their VIP's social capital were positively related to youth's grades and educational expectations one year later. Similarly, Haddad, Chen, and Greenberger (2010) conceptualized social capital in a similar sense, using VIP's educational attainment, employment status, and occupational prestige as their measures of social capital. Unlike Chang and colleagues (2010), they found differences in VIPs social capital did not impact youth's outcomes. Instead, they found VIPs' 
psychological characteristics made unique contributions to youth's self-esteem and problem behaviors. They posited that social capital might be less important than psychological characteristics in the formation of adolescent-VIP relationships. Given that psychological characteristics are related to bonding social capital, their findings could be interpreted as indicating that bonding social capital may be more important than bridging social capital to the formation of youth-adult relationships that then impact youth outcomes. The conflicting findings about bridging social capital between the two studies leads us to consider that viewing social capital as VIP economic and social characteristics alone might not be the most accurate method to assess bridging social capital.

Sullivan and Larsen (2009) explicitly explored how bridging social capital, under Putnam's (2000) definition, operates in YARs. The authors conducted in depth interviews to examine how adolescents can benefit from high resource community adults in seven primarily urban youth programs, which consisted of program advisors and 71 ethnically diverse students. Through these key relationships, youth described obtaining valuable information, skills, and access to adult worlds, even when relationships were brief. These findings provide support for bridging social capital as a source of information and assistance from adults.

\section{Studies of Psychological Resources}

Few studies aim to examine bonding social capital, as most studies conceptually conflate social capital with economic resources or social connections to networks, disregarding psychological resources. However, Brewster and Bowen (2004) conceptualized social capital as a psychological resource when they examined teacher support and school engagement of Latino middle and high school students. The authors considered teacher support as the degree to which teachers listen to, encourage, and respect their students. The authors found significant 
associations between youth's perceptions of teacher support and school engagement; as perceptions of teacher support increased, levels of problem behaviors decreased and levels of school meaningfulness increased. The authors asserted that these findings point to the importance of adult social capital for youth. In regards to teacher social capital, they felt the support offered by teachers affects school engagement and thus educational attainment (Brewster $\&$ Bowen, 2004). Though the authors only examine psychological resources, their study provides insight into what bonding social capital might look like in YARs; that is, emotional support might be a component of bonding social capital.

\section{Exploratory Studies of Social Capital}

There are several studies that have explored social capital generally and found what we consider to be evidence of both bonding and bridging social capital. In a study of youth's relationships with teachers, Stanton-Salazar (2001) defined social capital generally as the value of a relationship that provides support and assistance in a given social situation. Through indepth interviews with youth, he found that Latino students reported a lack of social and academic support from teachers and peers, and feelings of disconnection as reasons for dropping out of high school. He posits that direct assistance and certain types of social support from teachers are aspects of social capital.

Jarrett, Sullivan, and Watkins (2005) conceptualized social capital as economic resources and social connections to networks. They theorized that resource-rich or resource bearing adults and intentional programmatic efforts could bring youth and adults together in a way that produces or increases youth social capital. In their in-depth qualitative study of youth $(\mathrm{n}=34)$ enrolled across three urban youth programs, they found that resource-rich adults provided youth access to information, direct assistance, exposure to adult worlds, support, and encouragement. 
While the authors explicitly analyzed the data for economic and social resources, they also found evidence of psychological resources in support and encouragement. From this study, it seems that bridging social capital comes in the form of adults providing information, direct assistance, and exposure to adult worlds to youth. In addition, bonding social capital comes in the form of emotional support and encouragement from adults.

\section{Social Support and Social Capital}

Across studies of social capital, there are suggestions that certain types of social support might be related to social capital (e.g. emotional might be related to bonding social capital via Brewster \& Bowen; see table 1). Wills and Shinar (2000) identified and defined five specific types of social support: instrumental, informational, validation, emotional, and companionship. Instrumental support involves adults giving concrete, practical assistance when necessary. Informational support involves adults providing knowledge, advice, or guidance for youth. Emotional support involves adults being available and listening to youth when they are having problems, while also providing indications of caring, acceptance, empathy, trust, and love. Companionship support involves adults being available for participating in social and leisure activities with youth. Validation involves adults providing positive confirmation about the appropriateness of youths behaviors; it has also been called feedback or social comparison. While there have been many studies of social capital that have found different types of social support to be related to social capital, no study to our knowledge has directly explored the association between social support and social capital. This is important because while researchers studying social capital have been largely unclear in their definitions and measurement of the construct, researchers examining social support have provided more concrete 
and clear definitions and consistent approaches to measurement. Finding a potential relation between these two resources can allow for clearer assessment and better measurement.

This study expands on previous literature by utilizing in depth interviews with youth and adults to examine bonding and bridging social capital in youth-adult relationships. In addition, we explore the relation between social capital and social support. In following with our theoretical definition, we examine both youths' and adults' perceptions of the support provided in those relationships. Previous studies of social capital in programs meant to engender social capital suggested there might be something inherently different about youth who choose to engage in such programs (Jarrett, Sullivan, \& Watkins, 2005); therefore, to avoid this selection bias, we examine social capital in naturally occurring relationships. We used the following research questions to guide our exploration of social capital:

1) How does social capital look in youth-adult relationships, using the proposed definition as a frame?

a) In what ways, if any, are bonding and bridging social capital related to different types of social support?

2) In what ways are youths' and adults' perceptions of social capital within youth-adult relationships similar or different?

\section{Methods}

This paper draws on data from a larger mixed methods, longitudinal study of youth-adult relationships. Adolescents (ages 12-17; N=289) were recruited from a mid-sized Atlantic city through local youth programs, schools, and community settings. A subsample of 41 youth were then purposively selected for in depth interviews at six time points across three years. Participants were purposively selected to create a sample that was balanced by gender and age 
group (middle versus high school) and represented as much as possible a variety of psychometric properties (e.g. attachment style), racial/ethnic and SES backgrounds, and networks of relationships with important adults. The majority of the interview sample is white $(80 \%)$ and female $(54 \%)$. With each interview the youth complete a pre-interview survey that includes various demographic and psychosocial measures. During each interview the interviewee is asked to name a significant adult (see definition below; herein referred to VIP). At Time points 1, 3, and 5 researchers interview the nominated VIPs, if given permission from the youth. At Time 1 the VIP response rate was $65 \%$.

\section{Sample}

For the purposes of this paper we only included youth for whom we had two time points of interviews as well as interviews with their VIP. Thus, our sample for this paper includes 24 youth (with two interviews each) and 23 VIPs (one VIP was nominated by two youth). All names in the study are pseudonyms, selected by the participants themselves. In rare cases, we changed a pseudonym if two youth or adults chose the same name or selected a name that could be potentially identifying for the individual.

A majority $(n=19)$ of the sub-sample of youth identified as European American. Three youth identified as African American, while one youth identified as Hispanic American, and one youth identified as multiple races. Half of the youth in the sub-sample identify as female. At the time of the first interview the youth ranged in age from 13-17 $($ mean $=14.89$; median $=15)$.

The VIPs represented a variety of roles: teachers $(n=6)$, coaches $(n=3)$, other non-kin adults $(n=13)$, and non-parental kin $(n=5)$. Of the VIPs, 59\% identified as female. Of the 19 VIPs to supply a date of birth they ranged in age from 29 to 75 years of age at the time of the VIP Time $1(\mathrm{~T} 1)$ interview $($ mean $=46.68 ;$ median $=44)$. 


\section{Interview Protocols}

All of the interviews were conducted by the research team, which consists of faculty, doctoral students, masters' students, and research specialists. The majority of the interviewers are women (84\%) and racially identify as White (71\%) and Asian/Pacific Islander (29\%). All interviews were recorded and transcribed and were on average an hour long (ranging from 30min to $180 \mathrm{~min}$ ). Interview locations were chosen by the participants and were conducted at the university, at the participants' homes, at public locations (e.g. library), and at participants' workplaces.

Youth interview. At each time point the youth are asked to nominate a significant adult. We define a significant adult as “...persons you count on and that are there for you, believe in and care deeply about you, inspire you to do your best, and influence what you do and the choices you make" (Hirsch, Deutsch, \& DuBois, 2011). Then using a semi- structured interview protocol we asked questions to better understand the development and maintenance of these relationships including questions such as how they know the VIP, the types of things they do together and talk about, as well as the types of support the VIP provides. Youth were asked about their relationship with the T1 VIP regardless of whether or not they nominated the VIP again at the second interview. During T2 we asked questions about the current nature of their relationship and if there were any changes since the prior interview.

VIP interview. The VIPs were asked questions about their relationship with the youth who nominated them. The questions are closely aligned with the youth protocol to ensure easy triangulation of the youth's and adult's perceptions of the relationship, such as what types of things they do together and talk about. We also asked questions about the each VIP's interactions with youth in general. 


\section{Analysis}

All data for this study was coded and analyzed using Dedoose version 6.1.18, a web based mixed methods data analysis application. Members of the larger research team initially coded all interviews for themes related to the overall study (e.g., social support). Analysis for this paper sometimes drew on this initial coding and, at other times, specifically omitted consideration of the initial coding to allow for conceptual coding that was not affected by prior interpretation of the data, as will be described below.

Research question 1: In order to explore the extent to which the definition we proposed is empirically supported by the data, three members of the larger research team blind coded the youth interviews for bonding and bridging social capital; that is, they coded interviews without the presence of any previous coding conducted by the larger research team (e.g. social support). The coders were given the following definitions: Bonding social capital is the value that is produced from connections between people that already know one another or share a common identity and is useful for psychological well-being, engendering reciprocity, and reinforcing exclusive identities (Putnam, 2000). In youth-adult relationships, bonding social capital is likely the mechanism that engenders trust and mutuality between youth and adults; that is, after receiving psychological resources, youth may feel closer to adults and become more open to receiving other types of support. Bonding social capital is informally referred to as what is useful for youth to "get by." Bridging social capital is the value that is produced from connections between people from different groups and is useful for the expansion of identities, fostering reciprocity, disseminating knowledge, and personal advancement (Putnam, 2000). In youth-adult relationships, bridging social capital is useful for connecting youth to new information and social networks, that the youth most likely would not have had access to if not for their relationship 
with the adult connector. Bridging social capital is informally referred to as what is useful for youth to "get ahead" (see Appendix B for codebook). The first author trained the coders by reviewing the definitions with them and coding two youth interviews not included in our subsample for the presence of bonding and bridging social capital. All three authors then coded a total of eight youth interviews, meeting frequently to discuss questions and ensure coding fidelity. Once all coders established consistency with coding applications, they coded the 40 remaining transcripts separately. Each transcript had two coders who then met once coding was completed to reconcile discrepancies in coding. Overall, coders reached $90 \%$ agreement on all transcripts and the first author made executive coding decisions on unresolved questions. Once coding was completed the authors analyzed excerpts inductively for process descriptions of the development of the two types of social capital.

Research question 1a: After social capital coding was completed, the first author created an inventory of social capital excerpts in Microsoft Excel. Based on previous empirical examinations of social capital, each excerpt was documented for overlap with social support codes. Social support coding was previously completed for the youth interviews, as documented in Varga, Johnson, Yu, Deutsch, and Ehrlich's (2016) study of social support. Additionally, when we examined the excerpts that had been coded for social capital, an additional theme that the larger research team had coded for, mutuality, emerged as frequently overlapping with social capital and social support. Mutuality, which is characterized by shared or reciprocal relational interactions, has been noted as a factor in developing close mentoring relationships (Rhodes, 2002). Thus, due to its presence in the data, and its importance in the literature in youth-adult relationships, mutuality was considered in further analysis and interpretation. Once the inventory was complete, the first and second author analyzed the excerpts for potential patterns in overlap. 
Research question 2: We examined youth on a case-by-case basis, conducting a comparative analysis of their interviews with their VIPs. We analyzed VIP interviews for overlap or divergence in youth's descriptions of social capital. We examined VIPs responses to questions that the youth were also asked, such as "do you help youth with homework" and compared their answers to youth reports. In addition, we analyzed VIPs responses of their perceptions of their relationships. For example, "what do you think youth gets from this relationship? We then compared that information to the resources youth report receiving from VIPs.

\section{Findings}

\section{Evidence of Social Capital}

Within youth's descriptions of their relationships with important adults, social capital was a prevalent theme. Overall, there were 134 excerpts coded for social capital across the 48 youth interviews, representing 50 instances of bridging social capital and 84 instances of bonding social capital. Across time points, $76 \%$ of the youth in our sample described having both bonding and bridging social capital within their relationships. Bridging social capital often came in the form of economic (e.g. employment) and social (e.g. networks) resources. Bonding social capital often came in the form of psychological resources (e.g. emotional support), which helped facilitate youth's relationships with their VIPs. In addition, $98 \%$ of the social capital excerpts overlapped with at least one type of social support. It is important to note, however that there were 462 instances of social support overall; the vast majority of youth's discussions of social support, therefore, did not co-occur with social capital. So while social capital highly overlaps with social support that relationship does not work in both directions; the two concepts are not synonymous. Particular patterns in overlap are discussed in depth with each type of social capital below. 
Bridging. We found instances of bridging social capital most often in responses to the questions “do you learn things from VIP," “does VIP give you advice," and “does VIP help you with things," which were originally meant to solicit examples of instrumental or informational support from youth. Indeed, $78 \%$ of the bridging social capital excerpts overlapped with both instrumental and informational support. In our study, the combination of VIPs providing youth with concrete assistance and information or advice in an area that was important to the youth resulted in what youth felt was their advancing towards their goals.

Educational advancement was a common area in which VIPs were reported to provide bridging social capital. For example, PhilishaQueesha, a 14 year old male, described how his VIP gave him advice, "for the application at [private boarding school], he told me to probably not do anything extra because he does admissions at [University], so he told me that it's probably not a good idea to do extra things. Because sometimes the admissions people, they'll get kind of angry if you put anything extra on your application.” The perspective that PhilishaQueesha's VIP gave him was drawn from knowledge he gained from his work in admissions and likely is not advice the participant would have gotten from anyone else in his network. Further, PhilishaQueesha requested a letter of recommendation from his VIP and was later admitted to the school. Another example comes from Colt who described how his VIP, a family friend who had majored in English in college, helped him improve his writing skills, which he felt were important to his academic performance. By the second interview, Colt had finished his junior year and turned to his VIP for college preparation assistance:

she’s helped out a lot recently because...- I just finished junior year for high school. And that's a big year, and since she already had one of her daughters go through that, 
she helped me out with certain classes to take, or certain things I need to focus on, and really make sure I do well, and when to take the SAT, and stuff like that.

Colt, the oldest child in his family, emphasized throughout his interview that he sought out his VIP's advice over his parents because his VIP's daughter just completed her first year at college and therefore his VIP had more recent, reliable experience with the college process than his parents. Rachel, another junior, echoes this sentiment with her VIP, who is an administrator at a large university:

she's a good sounding board for ideas and things in my life, especially right now with deciding what college to go to. She's not my mom so she has a different perspective on my future than my mom does. And I think sometimes my parents probably get caught up a little bit in the, I don't want to say in the academic side of it, but [VIP] will just take into account more so the other things that will make a college experience, like a college experience.

Rachel went on to explain that her VIP gave her advice about choosing a college that would build her entire character to help her to be well rounded and successful after college. Rachel ultimately decided to go to the college that her VIP felt would be better for her overall.

Rachel's example also overlaps with another area in which bridging social capital was found, more general life advice that youth felt could be related to their future professional or social success. Examples in this area were less concretely tied to situations than educational advancement. For example, Katherine, a 15 year old, explained what she learns from her family friend VIP: "well she's in the housing department, so like how to deal with money there, so like what to pay for in the dorms and what's the better decision." She explains that this is important to her because "it shows me the bigger picture about like what's more like in every situation- 
pick the most, it might not be the right choice, but what's going to help me in the long run." Katherine's VIP used work situations to engage her in discussions surrounding decision making and future planning, skills that she felt will help her be successful in the future. Another participant, Skye, described how her VIP, a family friend, helped her navigate through social situations: "she's had two girls so she knows just like normal stuff that you'll go through in like middle school and like with your friends and everything. So she has a lot of good advice since she's had two girls that are really similar to me." Skye, the only girl in her family, went on to discuss her belief that her VIP's experience raising two daughters allowed her to provide accurate predictions of outcomes and advice that helped Skye remain uninvolved in negative social situations.

Youth also described many instances of bridging social capital in areas that were personally important for them to advance in, most often sports. For example, PhilishaQueesha described seeking advice from his soccer coach:

well one year, it was the year that I switched to the [community soccer team], I called him and asked him which team I should be on, if I should stay with him or go on the [community soccer team]. And then we talked about it for a while, and then he told me that I should go with the [community soccer team] because that would be a better experience for me because it would be with the better players.

This VIP drew on his knowledge of the skill levels of players on the community team and his knowledge of PhilishaQueesha's needs and abilities to advise PhilishaQueesha in a way that would likely lead to advancement in his soccer. In a non-sports related example, an 18-year-old student McMolnakerson described how his automotive technology teacher fostered an interest and expanded his knowledge and skills in fixing cars. McMolnakerson provided several 
examples of reaching out to his VIP outside of class for help with his car and how he appreciated his VIP's willingness to help “because my parents don't - they know that I love cars but they never ask me about it or take interest in it and Mr. Johnson does." In both PhilishaQueesha and McMolnakerson's examples, the VIPs provided youth with information unique to their positions that helped them grow in areas that were personally important to them. It is likely that they would not have gained the information and assistance from anyone else in their networks.

Across our analysis of the excerpts it became clear that instances of bridging social capital in our youth-adult relationships were characterized by: (1) the expansion of youths' knowledge or networks, and an alternative perspective (mostly to parents), (2) youth intentionally seeking out assistance and information, and (3) the information and assistance received being uniquely related to the adult's specific occupation or life experiences. When all of these conditions were present, it led to youth feeling that they advanced in an area that was important to them (see figure 1).

[Insert figure 1 here]

Bonding. Bonding social capital was most often coded in youth's responses to the questions "how close do you feel to VIP," "does VIP do things to let you know that they respect you," and "how does being with VIP make you feel." These questions were meant to uncover the processes that led to close youth-adult relationships. Initially, there were no clear patterns of overlap between the social support codes and the bonding social capital excerpts; that is, where bridging social capital excerpts had high code co-occurrence with only instrumental and informational support, bonding social capital excerpts had code co-occurrence with different combinations of all five types of social support. However, further analyses of the bonding social capital excerpts revealed a process of how bonding social capital appears to develop in these 
relationships. This process appears to rely on the presence of social support and other social processes in particular combinations over time (see figure 2).

The process of developing bonding social capital appears to start at having companionship social support. Every youth in our sample was able to describe general descriptions of initial bonding over shared identity or interest with their VIP. For example, Skylar, 13, explained that in the beginning of her relationship with her VIP, she appreciated how her VIP was really "nice" and "funny." She goes on to say that knowing they shared a similar interest in soccer in the beginning of their relationship was a "big key." Karen, 17, echoed this sentiment "but he started out as my coach, so we sort of had something in common [volleyball]." Another student, Connor, 17, says "we both love math, which is where it kind of starts." As these examples illustrate, youth were able to pick up on their VIPs' personalities and the similarities they shared with them in terms of social and academic interests. While these interactions alone could solely be considered companionship social support, they function as a facilitator to youth feeling more open to future interactions with the VIP and are a necessary precursor to bonding social capital.

The next step in the process of developing bonding social capital as it occurred in our data is comprised of youth's deeper descriptions of closeness due to their VIP displaying a sense of care for them, often characterized by a combination of companionship, emotional support, and instrumental support. For example, Poncho, 16, said, "he kind of talked to me about eating habits, and I don't have any problems or anything, but just - I wasn't eating enough I guess. And he - the fact that he showed that much concern made me feel closer." Despite it being within the track coach's responsibilities to make sure his runners are eating enough, Poncho felt his concern allowed her to feel close to him. Bob, a 16-year-old student describes liking his 
teacher's sense of humor and lightheartedness (an aspect of the first layer of bonding social capital) but it was his attention and dedication to helping him improve in Spanish that helped him feel close to his VIP:

I just wasn't good at it because I didn't - I’ve never been good at learning languages. So but he really helped out just overall. And he kind of noticed right away that I was behind. So right from the get-go, you could say, he was helping me out... He always offers, if I need any extra help or anything, to come in...

For Bob, it was not only his teacher's knowledge in Spanish that facilitated a sense of closeness in their relationship but also that his teacher made himself available for "extra help or anything." Bob perceived these interactions as being indicative of his VIP's level of care towards his learning and well-being. Also included at this layer are descriptions of feelings of equality in interactions. For example, Connor, 17, explains of his teacher “...it's more like he’s collaborating with me almost than it is teaching at me. And it feels more - I don't know, like we're on an equal footing, I guess. I'd consider him as a friend. A trusted friend, I guess would be a good description. Obviously he's not a peer because he is much older than me. But I'd still say he is." Though Connor cannot identify how his teacher created feelings of equality, he acknowledged that it helped him feel closer to his VIP. Another student, Bartholomew, 17, described how he felt close to his running coach because he accompanied him during practice runs when he was injured: “just working out together helps because it's like we're both going through the same thing" (emphasis added). This step in the process of developing bonding social capital requires the interaction of several different types of social support, most often companionship, emotional, and instrumental, which combine to contribute to a deeper sense of closeness and foster feelings of trust. Any one of these social supports coded alone would be 
unlikely to lead to a deep sense of closeness of feelings of trust. For contrast, here is an excerpt solely coded for emotional support from John, 13, about why he feels close to his VIP, a family friend, "like when my grandma died [my VIP] was always comforting and stuff." While John reports feeling close to his VIP, there is a notable lack of other types of social support from his descriptions of his VIP: “yeah she's nice to everybody. I don't know. I guess she like sometimes could ask me for something. I mean like it's not like really important to her but its just showing that she cares enough I guess." His descriptions indicate of a more superficial sense of closeness, one not necessarily leading to feelings of trust or bonding social capital.

The previous steps lead to bonding social capital, which is comprised of youth's descriptions of interactions characterized by validation social support, mutuality, authenticity, trust, and respect. Katherine said she knew her VIP respected her because "Well, sometimes if I know I do like bad stuff and my mom tells [VIP], like stuff that I will do, but like, she won't stop, like, supporting me, so she's always there." Across age groups and genders, youth's descriptions of this layer of bonding social capital described a space where they felt they could be authentic and validated. PhilishaQueesha describes why he feels his relationship with his VIP is unique "I know that he respects me and like he accepts how I am. So I don't have to worry about being any different with him." Raegan echoes "I don't feel like she judges me, and she doesn't like put down what I'm saying or say it's like wrong to feel this way or whatever. She just like understands and tries to help." Bonding social capital appears to help youth feel more internally comfortable and confident. Further, the concept of mutuality emerged as highly integrated with bonding social capital excerpts. Particularly, we found evidence that when youth felt validated and accepted, they experienced feelings of mutual respect that prompted reciprocal behaviors. Scooter, age 14, said: 
In the past she's pulled me aside after, and let me know what I contributed was good. Because when I - it was when I joined the youth group, I was new, so I was a little shy, and I wasn't talking that much. But then by the end of the trip I was talking and she was letting me know that I was contributing good things. And that just made me want to contribute more.

Here, Scooter identified his VIP's validating actions as being directly responsible for their close relationship and Scooter's comfort with contributing to the rest of the group. Bob describes a similar process:

You kind of feel like they're - they respect you more almost when they start being casual and informal with you. I mean that kind of overflows because when you're in the classroom, you know that they're a nice person. You know that they care about your work and stuff. And that kind of makes you want to work harder, I guess, to please them and then do well.

Bob described a process of how the mutual respect in his relationship with his teacher, which was built on previous steps in the process of companionship and trust, motivated him to work harder in the classroom.

As evident throughout this section, there appears to be a process through which bonding social capital is developed within the youth-adult relationships. For the youth in our sample, there needed to be an initial feeling of companionship social support, which encouraged youth to be more open to interacting with their VIPs more. This was followed by interactions characterized by multiple types of social support, most often companionship, emotional support, and instrumental support, which led to a deeper sense of closeness and feelings of trust. Once these foundational interactions occurred, bonding social capital interactions emerged as being 
characterized by trusting, respectful, validating, and authentic interactions between the youth and the VIP. Instances of bonding social capital led to youth in our study feeling more confident and comfortable with themselves. Further, there were several instances in which youth described how these feelings encouraged them to act on and seek out opportunities for personal growth.

[Insert figure 2 here]

\section{Dyadic Analysis}

Analysis of the youth interviews in our study revealed detailed and specific descriptions of instances of bonding and bridging social capital. We conducted a comparative analysis of the VIP interviews to see if their perspective of the relationship reflected youths' descriptions. Specifically, we catalogued the reasons and examples that youth participants gave of bonding and bridging social capital and examined VIPs interviews for mirroring or matching descriptions. Overall, the VIP and youth's descriptions of bonding social capital in their relationships mirrored each other more frequently than did their descriptions of bridging social capital.

Bridging social capital. Using data from the youth interviews as a guide, we analyzed VIPs responses to the questions "does youth learn things from you" and "do you help youth with homework or other things?" Recall from earlier examples that youth provided concrete examples of bridging social capital tied to the VIPs employment or life experiences in response to these questions. About $39 \%$ of the VIPs provided descriptions of bridging social capital in their relationships that directly reflect their youth's descriptions in response to these questions. For example, PhilishaQueesha described how his VIP, Mark, helped him with his private school application and the decision to change soccer teams. Mark discussed that PhilishaQueesha often seeks his guidance for long-term goals and mentioned PhilishaQueesha applying to the private school as an example. Mark identified the specific situation that PhilishaQueesha reported and 
confirmed that PhilishaQueesha frequently initiates when seeking guidance for situations regarding his future, which we also gathered from PhilishaQueesha's responses. Similarly, Colt discussed how his VIP, Carol, used her knowledge gained as an English major to help him improve his writing. Carol echoed this in her interview when she discussed how she's helped Colt with homework: “....he had gotten two really bad grades on two papers, and I was an English major, so I helped him revise the papers...." While Carol was able to confirm that she has helped Colt with writing she went onto say, “....after I helped him rewrite them, he ended up getting a B, which is horrible as well. You know what I mean? It wasn't that we turned in this perfect thing, so that was kind of funny as well. I really wasn't that much help." From this it seems that Carol is not aware that Colt feels he has made great improvements to his writing overall due to her help and that this is important to him. This was a common theme in the VIP interviews. It was not unusual for VIPs to be unable to identify specific ways in which youth felt they were assisted or how central their assistance was to the youth. For example, Bartholomew reported that he learned many tips about running from his track coach to better his athletic performance but when asked the same question his coach, David, said:

I hope that he learns about - I mean, I hope that just by the way that I interact with him he's learning empathy, he's learning how to, or he's at least seeing a model of somebody who can express themselves, some sort of vulnerability, mixed with strength of leading and making decisions, and I mean, I guess as somebody that's a little bit further down the road, I hope he's learning how to be a man.

Here David did not provide any matching details about what Bartholomew reports learning from him and does not make any mention of track despite being a track coach. Instead, David described ideal values, norms, and behaviors he hopes he imparts to Bartholomew. In a similar 
example, JohnnyDepp, explained that his VIP provided alternative perspectives for potential career trajectories (e.g. college vs. military) that he felt no one else in his network could give him due to his VIP's past military experience. However, when asked what he thinks JohnnyDepp learns from him, his VIP said, "most importantly, I want them to be better people when they leave the track program. In the end, if their times get worse but they leave better people, with regards to being a team member, being a leader. That's what's really important."

It appears that VIPs in our study interpreted the question of "does youth learn things from you" very generally to mean, "what do you hope the youth learns from you." It's possible that youth might be learning these values from their VIPs but the youth interpreted the question to be asking for concrete examples of assistance. This difference in interpretation could be simply a function of age. Yet it could also reflect the youth driven nature of bridging social capital in our data. A condition of bridging social capital for youth in our data was that youth intentionally seek out information or assistance in some area that is important to them to advance in. While youth often identified particular aspects of VIPs employment or life experiences being instrumental in their assistance, those aspects are only one portion of the VIPs overall identity. The VIPs likely help youth in many ways and therefore it might be difficult for them to identify the particular ways in which they assisted youth, that youth found the most meaningful. Instead, what the adults discuss are ways in which they hope youth improve that are most important to them, such as "being better people" as Francis said. While there were inconsistency in the way VIPs and youth described instances of bridging social capital, they more frequently concurred on their descriptions of bonding social capital.

Bonding social capital. We do not ask the VIPs the questions from which most of the bonding social capital excerpts emerged in the youth interviews. Therefore, we read through the 
entire transcripts of the VIP interviews for the presence of bonding social capital. We found that bonding social capital emerged in the VIP interviews in response to the questions "what do you think the youth gets from your relationship" and "why do you think you were nominated by the youth." In $80 \%$ of the VIP interviews the descriptions of bonding social capital that were provided in response to these questions mirrored the descriptions of bonding social capital provided by the youth. For example, recall that Poncho felt her coach strongly cared for her and that allowed her to feel comfortable opening up to him. Fred, her VIP, reflected on why he thought he was nominated: “it's not fake or contrived when I talk with Poncho and have a run with her where we talk for just an hour straight.... I really care about what she's saying... it's sincere like on that day I hope that she saw this sincere person who kinda wanted to know what was going on.” Though Fred was unsure of exactly how Poncho felt, he was able to accurately identify the aspect of their relationship that Poncho felt bonded them. Similarly, recall that Bob described the complete process of bonding social capital to where his feelings for his VIP, due to respectful and mutual interactions, "overflowed" into his behaviors to work harder in class. His VIP George said (emphasis added):

I think certainly he probably would feel safe with me. I think I try to establish an environment in my classroom where students are safe and where students are free to express themselves. I don't think he has ever felt held-back or restrained in any way in my classroom. That's again, if you're thinking in stereotypes when you think of a student being in a classroom where they just felt like the teacher was lecturing and they didn't really have much input. I think he probably would say my classroom is a place where he could have input and be more expressive. 
Here George accurately identified how Bob felt about the relationship and how his behavior was likely a result of the space he created. This sentiment is echoed in another pair, Robert and Melissa. Robert previously described feeling more comfortable talking to Melissa about things that bother him than with any other teacher because she's the one who talks to him when he's behaving badly, which fostered feelings of respect for him. On her end, Melissa said, "I hope that I always allowed him to just be himself, and to say the things that needed to be said when things got to be heavy for him. I think sometimes - I also think I wasn't hard on him, but I wanted him to be held accountable." Melissa accurately identified how she made Robert feel as well as the behaviors that contributed to their relationship. Throughout all of these examples there is an aspect of bonding social capital gained that was not seen in the youth interviews: adult intentionality and self-awareness. In instances of bonding social capital from the youth perspective, it was not explicitly clear how aware or intentional or invested the adults were in fostering a relationship with the youth or creating a safe space. From the adult perspective, many of the VIPs describe actively trying to create a space that is nonjudgmental and open for youth. These findings suggest that bonding social capital might be more of a shared or mutual experience than bridging social capital. Though aspects of bonding social capital are more general (e.g. we get along) and therefore potentially easier to match than bridging social capital, adults were able to key in on the specific characterizations of how youth felt about the relationship and what it emotionally and psychologically provides them. VIPs descriptions were colored with concern and genuine care for how the youth feels in their relationship.

\section{Discussion}

In this paper, we examined whether social capital could be considered a combination of economic, social, and psychological resources which are accessed and exchanged through 
bidirectional interactions between youth and non-parental adults. In addition, we examined the potential relation between social capital and social support. Finally, we conducted a comparative analysis of youths' and their VIPs' descriptions of social capital to see if there were similarities or differences in the way each perceived experiences of social capital in the relationship. Through exploratory analyses of bonding and bridging social capital we found evidence of nonparental adults providing youth with all resources through providing information and assistance gained through employment or life experience, social networks, and psychological support. Further, while both forms of social capital relied on the presence of social support, our analyses revealed that particular combinations of social supports and other social processes were required to produce both types of social capital. Taken together, the different types of social capital represent potential pathways through which social support and other social processes (e.g. mutuality, trust) can interact to impact youth internally or externally.

Our analyses revealed that bridging social capital occurred through a combination of instrumental and informational social support to expand youth's knowledge or networks, the youth intentionally seeking information and assistance, and the help of an adult who's occupation or life experience made them uniquely qualified to assist youth, in particular in areas of importance to youth. Further, when youth gained bridging social capital from an adult, they felt that they advanced in an area that was important to them. Our characterization of bridging social capital expands on our previous studies of bridging social capital in YARs in several ways.

First, our results demonstrate that youth are active agents in gaining bridging social capital. This supports the use of a PYD frame in understanding social capital in YARs as it provides empirical evidence for the proposition that social capital is exchanged through bidirectional interactions (Varga, 2016; Lerner, 2005). Further, while many previous studies 
examine the presence of "resource rich" (i.e. higher SES) adults in youth's lives (Gaddis, 2012; Chen et al., 2003), our findings suggest that measuring youth's access of resources in YARs might provide a better of assessment of whether or not youth benefit from the relationships.

Second, our findings complicate the traditional economic view of resource rich adults that the bridging social capital literature has typically operated under (Dreher \& Cox, 1996) by demonstrating that youth are able to identify unique resources that different adults can offer them based on employment, life experiences, and education. Whereas much of the literature holds adults in higher SES standing than youth as ideal for increasing bridging social capital (Chen et al., 2003), our findings demonstrate that adults of similar SES standing but differing life experiences can also provide bridging social capital. Further, this finding highlights Putnam's (2000) assertion that bridging social capital operates horizontally and therefore includes adults of similar SES but with wider networks, an assertion that has not often translated to empirical examinations of bridging social capital.

Third, we found that youth discussed advancements in areas important to them, beyond education and career advancement. The majority of the bridging social capital literature is preoccupied with academic and career advancement and therefore we did not anticipate finding bridging social capital in other areas. However, youth in our sample described bridging social capital in multiple domains of their life. For example, we found that many youth in middle school or early high school placed heavy importance on athletic advancement. This could potentially be because developmentally, for these youth athletic performance is more relevant than college preparation. Similarly, Skye spoke in great detail about her VIPs assistance with her social interaction skills. Being in middle school, peer interactions were particularly salient to Skye. Her VIP's assistance in this domain has important potential implications, as some 
researchers have linked peer support and school climate to academic motivation and performance (Wentzel, 1998).

Some of our findings also suggest that bridging social capital can shift over time in ways that map onto youth's developmental needs. For example, Colt discussed how his VIP moved from helping him with writing to helping him with SAT preparation when he became a junior in high school. While Colt's examples are both academic in nature, we suspect that social capital in nonacademic areas might be able shift into social capital in academic areas once it becomes relevant for the youth. Youth who seek out social capital in nonacademic areas demonstrate that they are capable of seeking out social capital. Therefore, such youth may seek out academic social capital once it becomes more salient in their lives. Given the literature's previous preoccupation with academic and career advancement, our findings suggest it is important to be open to social capital in nonacademic areas.

Our analyses of bonding social capital suggest that bonding social capital is developed through a process, which relies on the presence of companionship, emotional, and instrumental social support. Ultimately, bonding social capital is characterized by trusting, respectful, validating, and authentic interactions between the youth and the VIP, which appear to help youth feel validated, confident, and comfortable with themselves. Rhodes (2002) contends that the presence of a close and supportive relationship may create an atmosphere of trust in which youth feel like they can share personal and emotional concerns with a significant other. This in turn may promote a sense of mattering and feeling important to a significant other, thereby strengthening self-esteem and other aspects of psychological well-being (Rhodes, 2002; Dubois \& Silverthorn, 2005). Rhode's conceptualization of the way in which supportive relationships can be effective is similar to what we found to be the process of developing bonding social 
capital in YARs. Moving beyond her conceptualization, we found that bonding social capital could foster mutuality and encourage youth to seek out opportunities for personal growth. On the topic of mutuality, Ehrlich and colleagues (2016) found that youth recognize and appreciate adults that minimize the power differential that typically exists in YARs, which might encourage reciprocity. We believe that bonding social capital engenders mutuality and drives the youth to want to contribute back to their relationships and contexts. Though previous studies have suggested that support and encouragement might be a part of social capital (Jarret, Sullivan, \& Watkins), we present the first explicit characterization of the process of developing bonding social capital to our knowledge. Further, theoretically, there have typically been negative connotations attached to bonding social capital due to its potential role in social reproduction and social exclusion (Putnam, 2000; Bourdieu, 1985). However, our PYD conceptualization of bonding social capital highlights that bonding social capital promotes deeper connections, improvements in internal competencies, and reciprocity in YARs (Varga, 2016; Lerner, 2004).

Finally, our comparative analyses revealed VIPs were more likely to mirror youth's descriptions of bonding social capital than bridging social capital. Though we noted why it might be more difficult for adults to key in on specific instances of bridging social capital rather then general feelings of bonding social capital, this finding along with the youth being active agents in acquiring bridging social capital, highlight the importance of considering the youth perspective when assessing social capital. Omitting the youth perspective might lead to an incomplete understanding of the social capital in their lives.

However, these findings might also provide insight into potential differences in relational processes between bonding and bridging social capital. That is, bridging social capital might be best assessed from the youth's perspective because it is the youth and the adult working together 
to move the youth forward. Whereas, the process of developing bonding social capital might engage the youth and adult more equally to move the relationship forward. That's not to say that bridging social capital is not important to the adult in the relationship. Bridging social capital might impact the youth and the adult more differentially than bonding social capital, making instances of bridging social capital less salient for the adult.

\section{Implications}

Our findings have several implications for examining and measuring social capital in youth adult relationships. First, we provide concrete characterizations of each type of social capital as they occur in youth's relationships with adults. Second, our use of social support language helps bridge the two literatures so that the social capital literature may begin to capitalize on the consistency that the social support literature has had in operationalizing social support. Third, the understanding that social support underlies both types of social capital provides a direction for measurement. For example, future studies may check to see if youth have instrumental and informational support as an initial check for the potential presence of social capital. In another example, knowing that companionship is a necessary precursor to bonding social capital provides a point of intervention for researchers looking to engender bonding social capital in YARs; that is, finding someone the youth already feels companionship for can help the process along. Finally, our findings with the divergence in VIP and youth perspective emphasize the importance of measuring the youth perspective in examinations of social capital.

In our study we found that VIPs were not completely aware of the bridging social capital they were providing to youth. This has implications for the way adults in helping roles (e.g. teachers, mentors) could consider the support they provide to youth. For example, in line with 
our finding that youth have changing developmental needs, adults could cater their support towards interactions and activities that youth would find meaningful as they age and transition from different contexts. Moreover, adults should consider they ways they could foster and strengthen their relationship with youth. This does not imply, however, that all relationships and interactions be perfect. Instead, adults should see their relationship with youth as a process, one that develops over time through a series of interactions.

\section{Limitations}

Our interviews did not include any direct assessment of social capital. Instead we relied on youth's descriptions of ways in which they felt their interactions with their VIPs helped them internally and externally. Therefore, more exploratory examinations using the suggested frame need to be conducted in different samples. Additionally, this study used social support as a frame based off of previous mentions of social support in the literature. It is possible that other frames could also be used to describe processes of social capital. Due to our examination of these constructs in naturally occurring relationships with adults who the youth perceive as significant, we are unsure if the processes found in our study would be similar in program assigned mentoring relationships or in other relationships where social capital might be natural given the adults role (e.g. college counselor). Future studies should examine social capital in youth's relationships with adults they do not consider significant and where institutional trust or distrust might be preexisting, using a similar exploratory method of analysis as used in this paper. In addition, our two time points of data extend over one year and so we were not able to assess long-term benefits of social capital. Future studies should examine social capital utilizing this framework over a longer time period. In addition, we are working with an ethnically homogenous sample with higher SES than the national average; therefore these results may not 
generalize to more diverse samples. Further, it is possible that social capital is developed and exchanged differently for youth who face more contextual barriers to developing relationships with adults.

\section{Conclusion}

Though social capital has been considered highly important and beneficial for youth development (Chang et al., 2010; Kao \& Rutherford, 2007) there has been little consistency across the literature in defining, measuring, or assessing social capital in youth-adult relationships. In a previous examination of the foundations of social capital (Varga, 2016), the author suggest that many studies have treated social capital as more of a product with differential impacts rather than examining the process of how social capital is developed and exchanged in YARs, thereby limiting our ability as a field to measure social capital. Further, many studies examine singular types of social capital (Chang, et al., 2010; Sullivan \& Larson, 2009; Brewster \& Bowen, 2004), providing a limited picture of social capital in YARs. In our exploratory examination of social capital in YARs, we found evidence for both bonding and bridging social capital in YARs and provided insights into how bonding social capital develops. Further, we provided characteristics of each, using language to connect social capital across literatures and provide concrete constructs that have previously established higher levels of uniformity in measurement (e.g. social support) in order to assist in future measurement and examinations of social capital. Ultimately, the findings in our study show that youth can be active agents in producing and accessing social capital, a characteristic that has been largely absent from the social capital literature. It is imperative that researchers continue this journey of conceptual clarity in order to fully understand this complex construct so that when youth come to adults for support, they are prepared to provide them with the complete support that they deserve. 


\section{References}

Bourdieu P. (1985). The forms of capital. In J. G. Richardson (Ed.), Handbook of Theory and Research for the Sociology of Education, (p. 241-58). New York: Greenwood.

Brewster, A. B., \& Bowen, G. L. (2004). Teacher support and the school engagement of latino middle and high school students at risk of school failure. Child and Adolescent Social Work Journal, 21(1), 47-67.

Chang, E. S., Greenberger, E., Chen, C., Heckhausen, J. and Farruggia, S. P. (2010), Nonparental Adults as Social Resources in the Transition to Adulthood. Journal of Research on Adolescence, 20, 1065-1082. doi: 10.1111/j.1532-7795.2010.00662.x

Coleman, J. S. (1988). Social capital in the creation of human capital. American Journal of Sociology, 94, 95-120.

Croninger, R., \& Lee, V. (2001). Social capital and dropping out of high school: Benefits to atrisk students of teachers' support and guidance. Teachers College Record, 103, 548-581.

Curran, E. (2007). The relationship between social capital and substance use by high school students. Journal of Alcohol \& Drug Education, 51, 59-73.

Dedoose Version 6.1.18, web application for managing, analyzing, and presenting qualitative and mixed method research data (2015). Los Angeles, CA: SocioCultural Research Consultants, LLC (www.dedoose.com).

Eccles, J. \& J. A. Gootman, Eds. (2001). Community programs to promote youth development. Washington, DC: National Academy Press.

Futch Ehrlich, V. A., Deutsch, N. L., Varga, S. M., Fox, C. V., \& Johnson, H. E. (2016). Leveraging relational assets for adolescent development: A qualitative investigation of 
youth-adult 'connection' in positive youth development. Journal of Qualitative Psychology.

Glanville, J., Sikkink, D., \& Hernandez, E. (2008). Religious involvement and educational outcomes: The role of social capital and extracurricular participation. The Sociological Quarterly, 49, 105-137.

Israel, G. D., Beaulieu, L. J., \& Hartless, G. (2001). The influence of family and community social capital on educational achievement. Rural Sociology, 66(1), 43-68.

Hirsch, B. J., Deutsch, N. L., \& DuBois, D. L. (2011). After-school centers and youth development: Case studies of success and failure. New York: Cambridge University Press.

Haddad, E., Chen, C., \& Greenberger, E. (2011). The role of important non-parental adults (VIPs) in the lives of older adolescents: A comparison of three ethnic groups. Journal of Youth and Adolescence, 40, 310-319. doi:10.1007/s10964-010- 9543-4.

Jarrett, R. L., Sullivan, P. J., \& Watkins, N. D. (2005). Developing social capital through participation in organized youth programs: Qualitative insights from three programs. Journal of Community Psychology, 33(1), 41-55.

Kao, G., \& Rutherford, L. (2007). Does social capital still matter? Immigrant minority disadvantage in school-specific social capital and its effects on academic achievement. Sociological Perspective, 50, 27-52.

Patulny, R. V. \& Svendsen, G. L. H. (2007). Exploring, the social capital grid: Bonding, bridging , qualitative, quantitative. International Journal of Sociology and Social Policy, 27(1/2), 32-51. doi: $10.1108 / 01443330710722742$ 
Puntnam, R. (2000). Bowling alone: The collapse and revival of American community. New York: Simon and Schuster.

Rosenfeld, L. B., Richman, J. M., \& Bowen, G. L. (1998). Low social support among at-risk adolescents. Social Work in Education, 20, 245-260.

Rhodes, J. E. (2002). Stand by me: The risks and rewards of mentoring today's youth. Cambridge, MA: Harvard University Press.

Stanton-Salazar, R. D. (2001). Manufacturing hope and despair: The school and kin support networks of U.S.-Mexican youth. New York: Teachers College Press.

Sullivan, P. J., \& Larson, R. W. (2009). Connecting youth to high-resource adults: Lessons from effective youth programs. Journal of Adolescent Research.

Thomason, J. D., \& Kuperminc, G. (2014). Cool Girls, Inc. and Self-Concept The Role of Social Capital. The Journal of Early Adolescence, 34(6), 816-836.

Varga, S. M. (in preparation). Conceptualizing social capital within a positive youth development framework: The case of youth adult relationships.

Wei, M., Russell, D. W., Mallinckrodt, B., \& Vogel, D. L. (2007). The Experiences in Close Relationship Scale (ECR)-Short Form: Reliability, validity, and factor structure. Journal of Personality Assessment, 88, 187-204.

White, M. J., \& Glick, J. E. (2000). Generation status, social capital, and the routes out of high school. Sociological Forum, 15, 671-691. doi:10.1023/A:1007515100190

Wills, T. A., \& Shinar, O. (2000). Measuring perceived and received social support. In S. Cohen, L. G. Underwood, \& B. H. Gottlieb (Eds.), Social support measurement and intervention: A guide for health and social scientists (pp. 86-135). Oxford: Oxford University Press. 


\section{Appendix C}

Table 1. Summary of Previous Studies of Social Capital

\begin{tabular}{|c|c|c|c|c|}
\hline Citation & Definition & Measurement & $\begin{array}{l}\text { Type of } \\
\text { resource }\end{array}$ & Social support \\
\hline $\begin{array}{l}\text { Chang, } \\
\text { Greenberger, } \\
\text { Chen, } \\
\text { Heckhausen, } \\
\text { \& Earruggia } \\
(2010)\end{array}$ & $\begin{array}{l}\text { "Social capital encompasses aspects } \\
\text { of the social environment that } \\
\text { provide an individual with access to } \\
\text { resources that make positive } \\
\text { outcomes more likely" (p 1067). }\end{array}$ & $\begin{array}{l}\text { VIP's } \\
\text { educational } \\
\text { attainment } \\
\text { and } \\
\text { engagement in } \\
\text { misconduct }\end{array}$ & $\begin{array}{l}\text { Economic } \\
\text { resources; Social } \\
\text { resources }\end{array}$ & $\begin{array}{l}\text { Instrumental } \\
\text { support; } \\
\text { informational } \\
\text { support }\end{array}$ \\
\hline $\begin{array}{l}\text { Haddad, } \\
\text { Chen, \& } \\
\text { Greenberger } \\
(2010)\end{array}$ & No theoretical definition provided. & $\begin{array}{l}\text { VIP's } \\
\text { educational } \\
\text { attainment, } \\
\text { employment } \\
\text { status, and } \\
\text { occupational } \\
\text { prestige }\end{array}$ & $\begin{array}{l}\text { Economic } \\
\text { resources; social } \\
\text { resources }\end{array}$ & $\begin{array}{l}\text { Instrumental } \\
\text { support; } \\
\text { informational } \\
\text { support }\end{array}$ \\
\hline $\begin{array}{l}\text { Stanton- } \\
\text { Salazar (2001) }\end{array}$ & $\begin{array}{l}\text { "He defined social capital as the } \\
\text { value of a relationship that provides } \\
\text { support and assistance in a given } \\
\text { social situation" (p 12). }\end{array}$ & $\begin{array}{l}\text { In depth } \\
\text { interviews } \\
\text { with youth }\end{array}$ & $\begin{array}{l}\text { Social resources; } \\
\text { psychological } \\
\text { resources }\end{array}$ & $\begin{array}{l}\text { Instrumental } \\
\text { support; } \\
\text { informational } \\
\text { support; } \\
\text { emotional } \\
\text { support } \\
\end{array}$ \\
\hline $\begin{array}{l}\text { Brewster \& } \\
\text { Bowen (2004) }\end{array}$ & $\begin{array}{l}\text { "Social capital includes the resources } \\
\text { that reside in human relationships } \\
\text { that help promote positive outcomes } \\
\text { for individuals" (p 50). }\end{array}$ & $\begin{array}{l}\text { Student } \\
\text { surveys } \\
\text { perceptions of } \\
\text { teacher } \\
\text { support }\end{array}$ & $\begin{array}{l}\text { Psychological } \\
\text { resources }\end{array}$ & $\begin{array}{l}\text { Emotional } \\
\text { support }\end{array}$ \\
\hline $\begin{array}{l}\text { Jarrett, } \\
\text { Sullivan, \& } \\
\text { Watkins } \\
\text { (2005) }\end{array}$ & $\begin{array}{l}\text { "Social capital as social relationships } \\
\text { that entail the transfer of resources } \\
\text { and provide positive benefits. For } \\
\text { individuals, engaged in social } \\
\text { interaction with other individuals or } \\
\text { groups provides resources which they } \\
\text { would not otherwise have access to" } \\
\text { (p 43). }\end{array}$ & $\begin{array}{l}\text { In depth } \\
\text { interviews } \\
\text { with youth }\end{array}$ & $\begin{array}{l}\text { Social resources; } \\
\text { psychological } \\
\text { resources }\end{array}$ & $\begin{array}{l}\text { Instrumental } \\
\text { support; } \\
\text { informational } \\
\text { support; } \\
\text { emotional } \\
\text { support; } \\
\text { validation }\end{array}$ \\
\hline $\begin{array}{l}\text { Sullivan \& } \\
\text { Larsen (2009) }\end{array}$ & $\begin{array}{l}\text { "Bridging social capital: contact with } \\
\text { people from circles outside their own } \\
\text { who provide access to otherwise } \\
\text { inaccessible information, } \\
\text { connections, and other assets" (p 2- } \\
\text { 3). }\end{array}$ & $\begin{array}{l}\text { In depth } \\
\text { interviews } \\
\text { with youth }\end{array}$ & $\begin{array}{l}\text { Economic } \\
\text { resources; social } \\
\text { resources }\end{array}$ & $\begin{array}{l}\text { Informational } \\
\text { support; } \\
\text { instrumental } \\
\text { support }\end{array}$ \\
\hline
\end{tabular}

*VIP = significant non-parental adult and is defined in the methods section of this paper 
Codebook

\begin{tabular}{|c|c|c|}
\hline Type & Coding Definition & Example \\
\hline $\begin{array}{l}\text { Emotional } \\
\text { Support }\end{array}$ & $\begin{array}{l}\text { Allow discussion of feelings, } \\
\text { expression of concerns/worries; } \\
\text { indicate sympathy, approval, } \\
\text { caring, acceptance of person }\end{array}$ & $\begin{array}{l}\text { "...there's not really a boundary that I } \\
\text { feel like I need to stop with her. I can } \\
\text { just be totally open and tell her } \\
\text { anything." }\end{array}$ \\
\hline $\begin{array}{l}\text { Instrumental } \\
\text { support }\end{array}$ & $\begin{array}{l}\text { Provide money, household goods, } \\
\text { tools, transportation, child care, } \\
\text { assistance with cooking, cleaning, } \\
\text { shopping, repairs }\end{array}$ & $\begin{array}{l}\text { "[VIP] took me in while my parents } \\
\text { went away and stuff like that." } \\
\text { "[VIP] did help me with an English } \\
\text { paper one time because she was an } \\
\text { English major" }\end{array}$ \\
\hline $\begin{array}{l}\text { Informational } \\
\text { support }\end{array}$ & $\begin{array}{l}\text { Provide information about } \\
\text { resources, suggest alternative } \\
\text { courses or action, provide advice } \\
\text { about effectiveness }\end{array}$ & $\begin{array}{l}\text { "[VIP] gave advice mainly about high } \\
\text { school and the transition from there } \\
\text { and just kind of like daily stuff- "this } \\
\text { is a good tip to do." }\end{array}$ \\
\hline $\begin{array}{l}\text { Companionship } \\
\text { support }\end{array}$ & $\begin{array}{l}\text { Provide partner for sports, outdoor } \\
\text { activities, movies, theater, } \\
\text { museums, restaurants, shopping, } \\
\text { parties, trips }\end{array}$ & $\begin{array}{l}\text { "[being with VIP] makes me feel like } \\
\text { I have like someone that I can turn to } \\
\text { when I need him. And like a good } \\
\text { friend that I can just go and do fun } \\
\text { stuff with." }\end{array}$ \\
\hline Validation & $\begin{array}{l}\text { Provide consensus information re } \\
\text { prevalence of problems, } \\
\text { normativeness of individual's } \\
\text { behavior/feelings, individual's } \\
\text { relative status in population. }\end{array}$ & $\begin{array}{l}\text { "when I do well on tests [VIP's] like } \\
\text { 'that's one of the higher scores in all } \\
\text { the sections. Good job.' One time I } \\
\text { got the highest score and [VIP] told } \\
\text { me that and I felt really good about } \\
\text { it." }\end{array}$ \\
\hline $\begin{array}{l}\text { Bonding Social } \\
\text { Capital }\end{array}$ & $\begin{array}{l}\text { Bonding social capital is the value } \\
\text { that is produced from connections } \\
\text { between people that already know } \\
\text { one another or share a common } \\
\text { identity and is useful for } \\
\text { psychological well-being, } \\
\text { engendering reciprocity, and } \\
\text { reinforcing exclusive identities }\end{array}$ & $\begin{array}{l}\text { "I know that he respects me and like } \\
\text { he accepts how I am. So I don't have } \\
\text { to worry about being any different } \\
\text { with him." }\end{array}$ \\
\hline $\begin{array}{l}\text { Bridging Social } \\
\text { Capital }\end{array}$ & $\begin{array}{l}\text { Bridging social capital is the value } \\
\text { that is produced from connections } \\
\text { between people from different } \\
\text { groups and is useful for the } \\
\text { expansion of identities, fostering } \\
\text { reciprocity, disseminating } \\
\text { knowledge, and personal } \\
\text { advancement }\end{array}$ & $\begin{array}{l}\text { "She helped me out with certain } \\
\text { classes to take, or certain things I } \\
\text { need to focus on, and really make sure } \\
\text { I do well, and when to take the SAT, } \\
\text { and stuff like that." }\end{array}$ \\
\hline
\end{tabular}




\section{Figure 1.}

\section{Deconstructed Model of Bridging Social Capital}

\begin{tabular}{|c|}
\hline $\begin{array}{c}\text { Youth } \\
\text { Condition }\end{array}$ \\
\hline $\begin{array}{c}\text { Youth has interest in } \\
\text { area of growth (e.g. } \\
\text { academic, athletic) }\end{array}$ \\
\hline $\begin{array}{c}\text { Adult } \\
\text { Condition }\end{array}$ \\
\hline $\begin{array}{c}\text { Adult has differing job or } \\
\text { life experiences from } \\
\text { youth }\end{array}$ \\
\hline
\end{tabular}

\begin{tabular}{|c|}
\hline $\begin{array}{c}\text { Relational } \\
\text { Interactions }\end{array}$ \\
\hline $\begin{array}{c}\text { Youth seeks out adult } \\
\text { assistance in area of } \\
\text { importance to youth }\end{array}$ \\
\hline Adult connects youth to \\
new information or \\
networks through \\
informational and \\
instrumental support \\
\hline
\end{tabular}

Youth

External Growth in

Area of Interest

\section{Figure 2.}

\section{Deconstructed Pyramid of Bonding Social Capital}

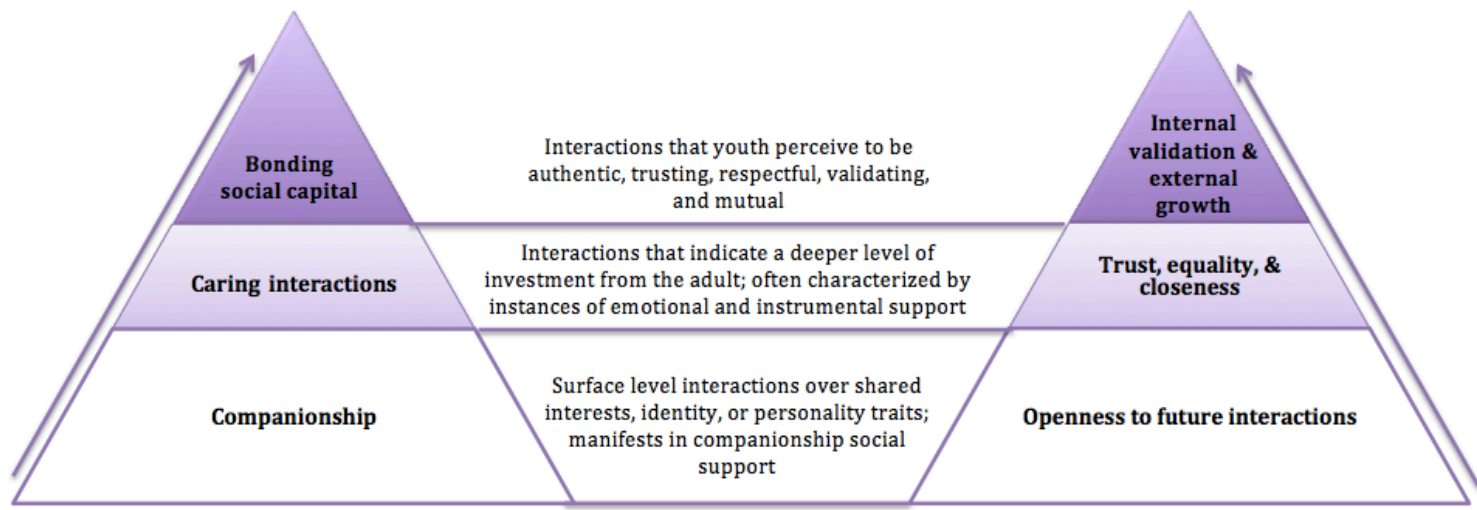

Stages of developing bonding social capital

Characterizations of

interactions at each stage 